\title{
Evolution of long-period stacking ordered structure and hardness of Mg-8.2Gd-3.8Y-1.0Zn-0.4Zr alloy during processing by high pressure torsion
}

\author{
W.T. Sun ${ }^{1}$, X.G. Qiao ${ }^{1 *}$, M.Y. Zheng ${ }^{1 *}$, N. $\mathrm{Hu}^{2}$, N. Gao ${ }^{2}$, M.J. Starink ${ }^{2}$ \\ ${ }^{1}$ School of Materials Science and Engineering, Harbin Institute of Technology, Harbin 150001, PR China \\ ${ }^{2}$ Materials Research Group, Faculty of Engineering and the Environment, University of Southampton, Southampton \\ SO17 1BJ, UK \\ * zhenghe@ hit.edu.cn, Tel.: +86451 86402291, fax: +8645186413922 \\ *xgqiao@ hit.edu.cn, Tel.: +86451 86402291, fax: +86 45186413922
}

\begin{abstract}
:
High pressure torsion (HPT) was performed at room temperature on a Mg-8.2Gd-3.8Y$1.0 \mathrm{Zn}-0.4 \mathrm{Zr}$ (wt.\%) alloy containing long period stacking ordered (LPSO) phase with a 6.0 GPa pressure. The microstructure evolution and hardening mechanisms were analyzed. TEM shows that, with increasing HPT strain, the LPSO lamellar-shaped and block-shaped particles experience kink bending, fragmentation and dissolution; and eventually a supersaturated solid solution with nanosized grains is obtained. The decomposition of LPSO phase at room temperature is attributed to the high defect concentrations generated in the LPSO lamellae and blocks, and the Mg-rich phase. With equivalent strains increasing to $\sim 6.6$ (16 HPT revolutions), an exceptional grain refinement to $52 \pm 2 \mathrm{~nm}$ is achieved, and the hardness is enhanced to $128 \pm 2 \mathrm{HV}$. A quantitative model shows the hardness increase is due to the combined effects of nanosized grains, high dislocation density and dissolved alloying elements. XRD line broadening analysis, thermodynamic modelling software and elemental mapping are used to support the mechanistic interpretations.
\end{abstract}

Keywords: Mg-RE alloy; Long period stacking ordered phase; Nanostructure; Hardening mechanism; High pressure torsion.

\section{Introduction}

Magnesium alloys are potential candidates for structural application in many fields owing to their low density, high specific strength and good damping capacity $[1,2]$. With the aim of developing ultrahigh strength, the addition of rare earth elements (RE) into magnesium alloys has been widely investigated $[3,4]$.
Long period stacking ordered (LPSO) phase contain $\mathrm{RE}$ and $\mathrm{Zn}$ atoms which arrange periodically in the $\mathrm{Mg}$ basal planes forming wellordered structures [5, 6], and they usually form as a lamellar structure inside the grains and/or as a block-shaped structure at grain boundaries (GBs) during solidification or subsequent annealing of Mg-RE-Zn alloys [7, 8]. Previous studies revealed 
that the mechanical properties could be regulated by controlling the morphology and distributions of LPSO phase $[9,10]$. Because the Young's modulus of the LPSO phase is higher than the $\alpha$ $\mathrm{Mg}$ matrix and the (0001) basal slip dominates its plastic behaviour, the intragranular lamellarshaped LPSO structures are usually considered to acts as fiber reinforcement to strengthen the alloy, and accommodate the local strain by kink deformation to improve the ductility [11-13]. The block-shaped LPSO structures located at GBs can also hinder the slide of dislocations, contributing to the strengthening of the alloy, but the microcracks are prone to initiate at the LPSO-Mg interface due to the generated strain localization and stress concentration [11, 14, 15]. As-cast LPSO-containing $\mathrm{Mg}$ alloys often exhibit low tensile strength because of a coarse grain structure, eutectic phases at grain boundaries and inhomogeneous distribution of coarse LPSO phase [16, 17], and cracks may nucleate and propagate along the interface between the massive LPSO and $\alpha-\mathrm{Mg}$ matrix close to the grain boundaries due to low bond strength of the interface and poor deformation compatibility [11].

The formation, growth and transformation of LPSO phase are influenced by chemical composition and processing parameters [6]. The evolution of LPSO phase in Mg-RE-Zn alloys during conventional thermomechanical processing has been reported in several works [12, $13,18,19]$. During the hot extrusion of an ashomogenized Mg-8.2Gd-3.8Y-1.0Zn-0.4Zr (wt.\%) alloy, abundant $14 \mathrm{H}$ LPSO lamellae precipitated in the deformed coarse grains, aligned along the extrusion direction [18]. During the extrusion of a Mg-8.2Gd-3.8Y-1.0Zn-0.4Zr (wt.\%) alloy containing a large amounts of 14H LPSO phase, the block-shaped LPSO particles at original GBs deformed and elongated along the extrusion direction. In the coarse deformed grains, the plateshaped LPSO structures within original grains reoriented with their basal planes parallel to the extrusion direction, while in the dynamic recrystallization (DRX) grains only solutesegregated stacking faults formed [19]. Largestrain hot rolling of an as-homogenized $\mathrm{Mg}$ 8.2Gd-3.8Y-1.0Zn-0.4Zr (wt.\%) alloy with reduction ratio $20 \%$, caused $14 \mathrm{H}$ LPSO lamellae to bend by the formation of kink bands $[12,13]$. As the rolling reduction ratio increased to $60 \%$, DRX occurred, accompanied by the partial dissolution of the lamellar-shaped 14H LPSO phase, and at the same time, fine globular LPSO phase particles precipitated at grain boundaries of DRX grains. As the rolling reduction ratio increased to $96 \%$, the $18 \mathrm{R}$ LPSO precipitated densely at the grain boundaries, while $14 \mathrm{H} \mathrm{LPSO}$ precipitated inside the grains [13]. These works suggest that it is impossible to achieve an ultrafine microstructure with well-dispersed LPSO phase particles using conventional thermomechanical processing methods.

Severe plastic deformation (SPD) is very effective for achieving an ultrafine microstructure in bulk metallic materials [20]. Amongst SPD techniques, high pressure torsion (HPT) processing has the potential for achieving the greatest grain refinement at room temperature by using extremely large torsional straining and high hydrostatic pressure to prevent cracking. SPD has also been applied to refine and disperse second phases effectively in different alloys, such as $\mathrm{Mg}$ alloys, Al alloys and pearlitic steels [21-24]. The evolution of the second phase particles during SPD depends on various factors such as their size, morphology and also the processing parameters. For LPSO particles in Mg-RE-Zn alloys, the 
evolution during friction stir processing (FSP) and equal channel angular pressing (ECAP) at elevated temperatures has been investigated [9, 25-27]. During FSP of the as-cast Mg-9.4Gd4.1Y-1.2Zn-0.4Zr (wt.\%) alloy at $\sim 500{ }^{\circ} \mathrm{C}$ the 18R LPSO lamellae dissolved, and fine LPSO lamellae with a width of $\sim 5-200 \mathrm{~nm}$ precipitated in the DRXed grains, which contributed to a higher strength and superplasticity in comparison with the as-cast counterpart $[9,25]$. During ECAP processing at $\sim 360{ }^{\circ} \mathrm{C}$ of the as-cast $\mathrm{Mg}-2 \mathrm{Y}-1 \mathrm{Zn}$ (at.\%) and Mg-4Y-2Zn (at.\%) alloys, 18R LPSO phase deformed by kinking and parts of them fractured into small particles, while nanosized 14H LPSO microcells dynamically precipitated [26-28]. The mechanical properties after ECAP were significantly enhanced due to the LPSO kinking and fine DRXed grains, but the extent of increase in strength and elongation decreased with increasing passes as the process of ECAP introduced micro-cracks at the interior of LPSO phase, which accelerated the growth and coalescence of the cracks during the subsequent mechanical test [26-28]. These studies implied that the mechanical properties of the LPSOcontained Mg-RE-Zn alloys are seriously sensitive to the grain size and the plastic deformation behavior of LPSO structures. As compared to HPT processing, due to the limited strain and high processing temperature of FSP and ECAP deformation, the unavoidable growth of $\mathrm{Mg}$ grains and the insufficient fragmentation of various LPSO phases would hinder a further optimization of mechanical property. Up to now, very little research on the evolution of LPSO phases during HPT at room temperature is reported, and the influence of their structural transformation on the evolution of mechanical property has not been elucidated yet.
In the present study, the $\mathrm{Mg}-\mathrm{Gd}-\mathrm{Y}-\mathrm{Zn}-\mathrm{Zr}$ alloy containing a large amount of $14 \mathrm{H}$ LPSO phase is deformed by HPT up to 20 turns at room temperature. The aim is to investigate the evolution of LPSO phase during HPT, its effect on microstructure refinement and mechanical properties of the alloy, and to derive the relevant mechanisms.

\section{Experimental procedures}

The ingot was prepared by direct-chill casting using high purity $\mathrm{Mg}(>99.99 \%)$ and $\mathrm{Zn}$, and high purity Mg-30Gd (wt.\%), Mg-30Y (wt.\%) and $\mathrm{Mg}-25 \mathrm{Zr}$ (wt.\%) master alloys, and its actual composition examined by inductively coupled plasma (ICP) analyzer was Mg-8.2Gd-3.8Y-1Zn$0.4 \mathrm{Zr}$ (wt.\%) [29]. The alloy was homogenized at $510{ }^{\circ} \mathrm{C}$ for $12 \mathrm{~h}$ followed by furnace cooling at an average cooling rate of $\sim 0.8{ }^{\circ} \mathrm{C} / \mathrm{min}$. This process causes the formation of a dense structure of LPSO lamellae in the matrix [11]. Disks with a diameter of $10.0 \mathrm{~mm}$ and thickness of $1.0 \mathrm{~mm}$ were cut from the heat-treated ingot, and then ground with abrasive papers on both sides to a final thickness of $\sim 0.85 \mathrm{~mm}$ with parallel broad surfaces. All the disks were processed by HPT at ambient temperature through $1 / 8,1,5,10,16$ and 20 turns under quasi-constrained conditions [30] using an imposed pressure of $6.0 \mathrm{GPa}$ and a rotational speed of $1 \mathrm{rpm}$. No damage or cracking was observed. In addition, after HPT processing of 20 turns, in order to confirm the occurrence of LPSO phase reformation, the sample was further annealed at $400{ }^{\circ} \mathrm{C}$ for $1 \mathrm{~h}$ followed by water quenching.

The microstructures of the materials before and after HPT processing were observed by a JEOL JSM 6500F field-emission scanning electron microscope (FE-SEM), and FEI Talos 
F200X transmission electron microscope (TEM) equipped with a Super-X energy dispersive spectrometry (EDS) with four windowless silicondrift detectors and operated at $200 \mathrm{kV}$ accelerating voltage. For TEM, a small disk of $3 \mathrm{~mm}$ in diameter was punched from the HPT-processed disk at a location centered at $2.5 \mathrm{~mm}$ from the centre of the HPT disk. This small disk was then mechanically polished to a thickness of $\sim 50 \mu \mathrm{m}$, and milled using a Gatan plasma ion polisher. The average grain sizes $d$ of HPT-processed samples were measured from TEM images by a modified linear intercept method [31-33]. The volume fractions of second phase particles in HPTprocessed samples were measured using backscattered electron SEM micrographs on the basis of the stereological concept [34] that in a randomly oriented planar section, the area fraction of particles is equal to the volume fraction of the particles. In order to obtain the area fraction, fifteen SEM images were obtained using Image $\mathbf{J}$ software [35]. The constituent phases of HPTprocessed samples were analyzed by X-ray diffraction (XRD). The XRD measurement was conducted using an X'Pert PRO X-Ray diffractometer equipped with a graphite monochromator using $\mathrm{Cu} \mathrm{K} \alpha$ radiation, operated at voltage of $40 \mathrm{kV}$ and electric current of $40 \mathrm{~mA}$. The microstrains $\left\langle\varepsilon^{2}\right\rangle{ }^{1 / 2}$ and crystallite sizes $D_{c}$ of samples are determined by analyzing the XRD line profiles via the Materials Analysis Using Diffraction (MAUD) software [36, 37]. The dislocation densities $\rho$ were estimated from the determined $\left\langle\varepsilon^{2}\right\rangle{ }^{1 / 2}$ and $D_{c}$ through the equation $\rho=\frac{2 \sqrt{3}\left\langle\varepsilon^{2}\right\rangle^{1 / 2}}{D_{c} b}[33,38,39]$, where $b$ is the Burgers vector.

Additionally,

the equilibrium phase diagram of the alloy was calculated by thermodynamic modelling using the latest available version (2017) of PanMg database in Pandat ${ }^{\mathrm{TM}}$ software (Compu Therm LLC) [40].

The Vickers microhardness changes of HPTprocessed samples with various revolutions were measured along the diameters using a Zwick microhardness tester under a constant load of 500 gf held for $15 \mathrm{~s}$. Each reported hardness value was determined by averaging values for four separate indentations at selected positions that are equidistant to the centre of disk, and error bars included in figures reflect a $95 \%$ confidence level. The estimated equivalent strain $\varepsilon_{e q}$ imposed on the disk is described according to the equation of $\varepsilon_{e q}=\frac{2}{\sqrt{3}} \ln \left[\left(1+\frac{\gamma^{2}}{4}\right)^{1 / 2}+\frac{\gamma}{2}\right][41,42]$, where $\gamma$ represents the shear strain $\gamma=\frac{2 \pi r N}{h}, r$ is the radial distance from disk centre, $h$ is the thickness of the disk and $N$ is the total number of torsional revolutions.

\section{Results and analysis}

\subsection{Microstructure evolution}

Fig. 1 shows the microstructure of as-heat treated alloy prior to HPT processing. The average grain size of the alloy in this condition is about $\sim 120 \mu \mathrm{m}$ with profuse LPSO lamellae throughout all the grains, and a very small amount of blockshaped LPSO phase particles dispersed randomly at the grain boundaries. The XRD work (see section 3.2) has identified the 14H LPSO phase as the only second phase that formed during processing and hence both the lamellae and block shaped particles are 14H LPSO phase. In Fig. 1(c) and (d), the $14 \mathrm{H}$ LPSO lamellae are oriented parallel to the basal planes in the $\alpha-\mathrm{Mg}$ phase. Elemental mappings in Fig. 1(e)-(i) show that LPSO lamellae are enriched with $\mathrm{RE}$ and $\mathrm{Zn}$ atoms. 

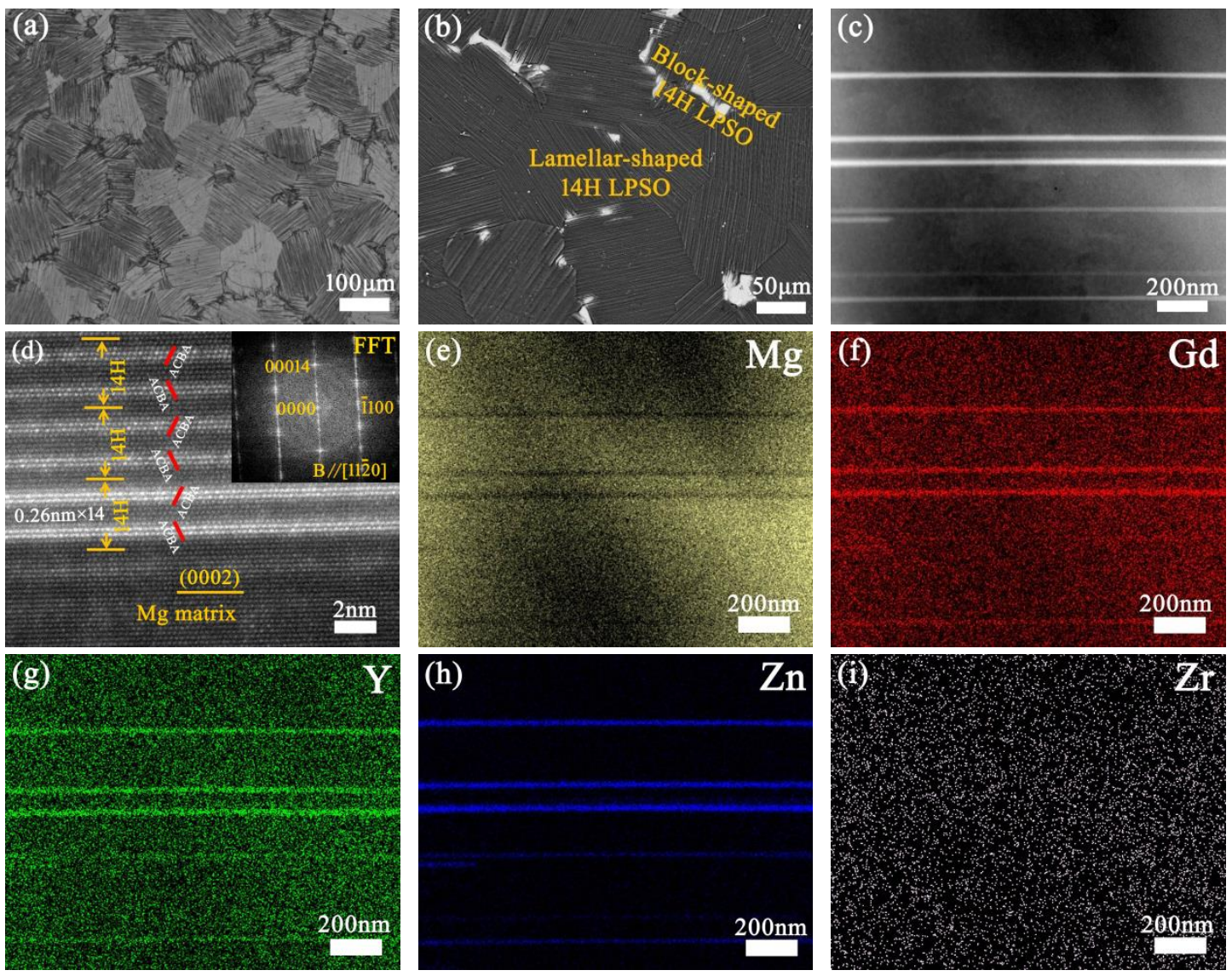

Fig.1 Microstructure of as-heat treated alloy prior to HPT: (a) optical micrograph; (b) backscattered electron SEM image; (c) high-angle annular dark field scanning transmission electron microscopy (HAADF-STEM) image; (d) Atomic-resolution HAADF-STEM image and inserted Fast Fourier Transform (FFT) image; elemental mappings of (c): (e) $\mathrm{Mg}$; (f) $\mathrm{Gd}$; (g) $\mathrm{Y}$; (h) $\mathrm{Zn}$ and (i) $\mathrm{Zr}$.

Fig. 2 shows SEM micrographs of Mg-Gd-YZn-Zr alloy after HPT deformation for different revolutions. At 1/8 and 1 turn of HPT processing, kink bands are generated in the deformed LPSO lamellae, as indicated by red arrows. After 5 turns and 10 turns, the LPSO lamellae are gradually transformed into several small fragments owing to the occurrence of kinking and cracking at the positions of turning points. As HPT deformation is increased to 16 turns, the lamellae have surprisingly vanished, implying that LPSO lamellae decomposed and dissolved into the $\alpha-\mathrm{Mg}$ phase forming a supersaturated solid solution. After HPT for 20 turns, a reasonably homogeneous microstructure is produced. Compared to the LPSO lamellae, the blockshaped LPSO particles are more resistant to fracturing, as their morphology nearly remained unaffected until 5 turns. With the number of revolutions increasing up to 16 , the original coarse block-shaped LPSO structures are gradually broken into smaller pieces. After 16 and 20 turns, the small fragments have sizes of $\sim 1-5 \mu \mathrm{m}$, and they are relatively homogeneously dispersed in the material. The volume fraction of the blockshaped LPSO phase particles is reduced from $\sim 9.7$ $\pm 0.5 \%$ at the initial heat-treated state to a $\sim 3.5 \pm$ $0.8 \%$ after HPT for 16 turns. No significant 
difference in amount of residual particles between

16 turns and 20 turns is detected by SEM.

HPT1/8

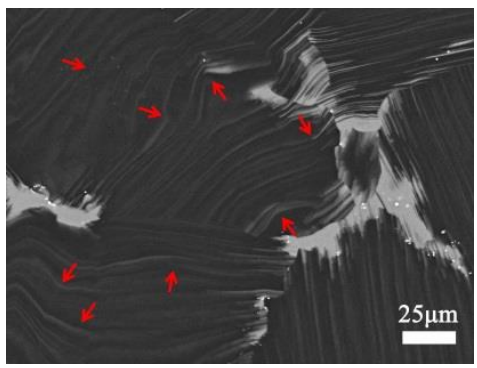

HPT10

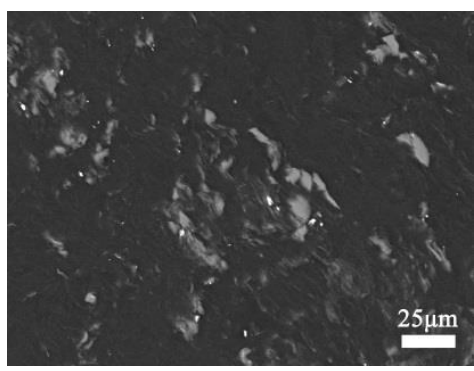

HPT1

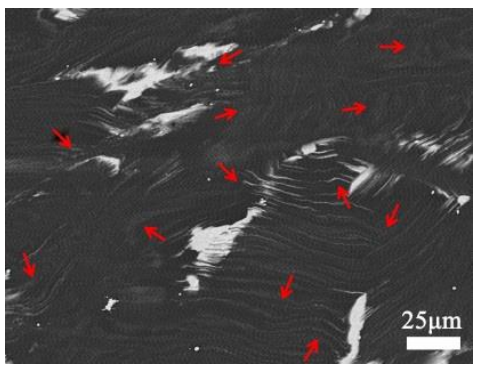

HPT16

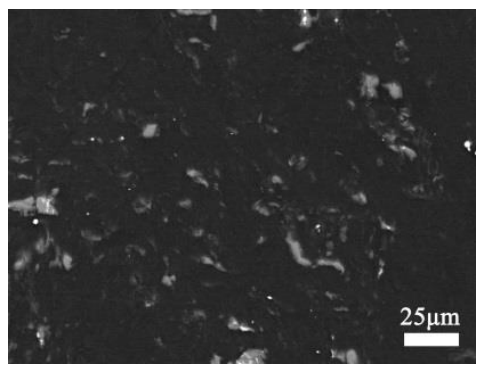

HPT5

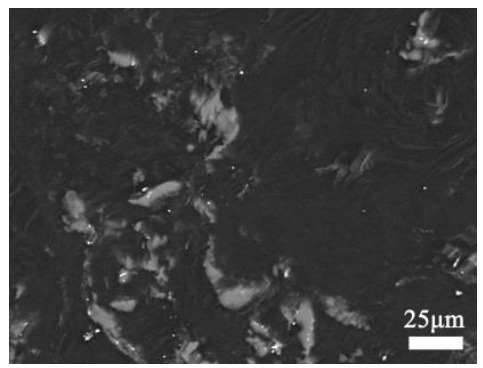

HPT20

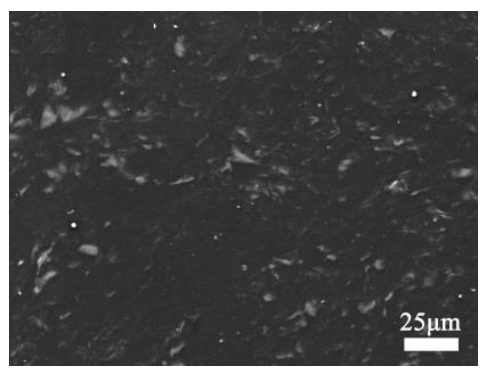

Fig.2 Backscattered electron SEM micrographs of heat-treated Mg-Gd-Y-Zn-Zr disks processed by HPT for various revolutions taken at positions close to $1 / 2$ radius, and the kink bands are indicated by the red arrows.

Fig. 3 exhibits TEM micrographs of the HPT1/8 sample. In comparison with the alloy prior to HPT, there is almost no change in the grain sizes after 1/8 turn (see Fig. 2). The TEM bright field image of typical microstructures within individual grains in Fig. 3(a) shows a high density of dislocations accumulated around LPSO lamellae inside coarse grains. The HAADFSTEM image and elemental mappings (Fig. 3(d)(h)) confirm that a few deformation kink bands are formed in the LPSO lamellae by shearing as marked by arrows in Fig. 3(b), which is in a good agreement with the SEM observations in Fig. 2. At kink bands the LPSO lamellae are effectively broken up as shown in Fig. 3(c). Compared with the initial state (prior to HPT), after 1/8 turn the boundary between LPSO and Mg matrix at the kink becomes obscure with an irregular contrast in HAADF images and non-uniform solute distributions in elemental mappings (Fig. 3(d)(h)). This is attributed to the occurrence of defects accumulation created by HPT, which can produce excess free volume and generate local strains/stresses around the interface.

After 1 turn, as shown in Fig. 4(a), there is still a high density of dislocations accumulated around the LPSO phase. At this stage, the thickness of the LPSO lamella (Fig. 1(c)) has become non-uniform (indicated as red and blue arrows in Fig. 4(b)), suggesting that solute atoms diffuse along the LPSO/Mg matrix interface. 

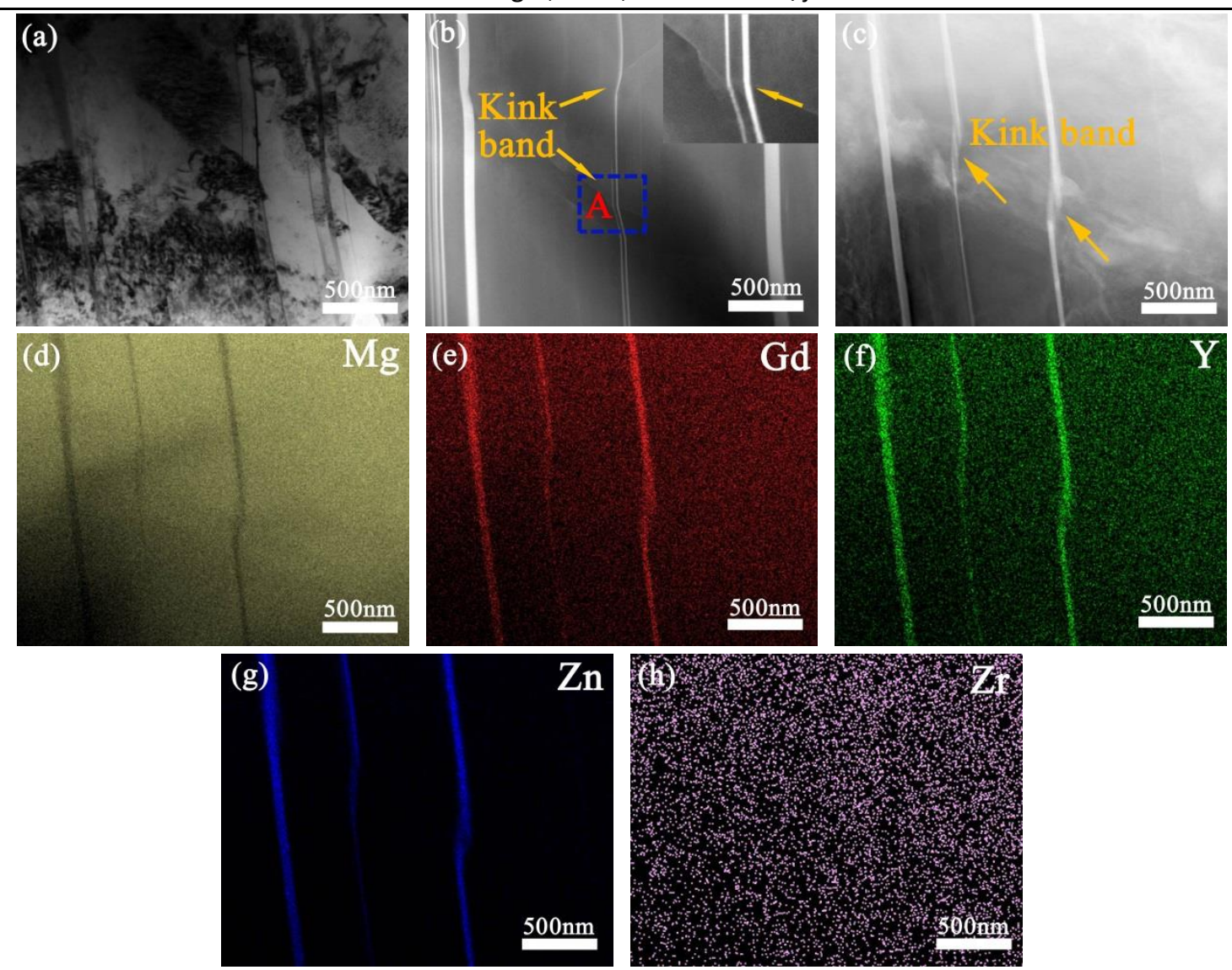

Fig.3 Microstructure of HPT1/8 ( $\left.\varepsilon_{\text {eq }} \sim 1.1\right)$ : (a) TEM bright-field image of dislocations pile-ups between lamellashaped LPSO phase; (b) HAADF-STEM image of kinked LPSO phase and the magnified image of region A inserted;

(c) HAADF-STEM image of kink band; elemental mappings of (c): (d) Mg; (e) Gd; (f) Y; (g) Zn and (h) Zr.
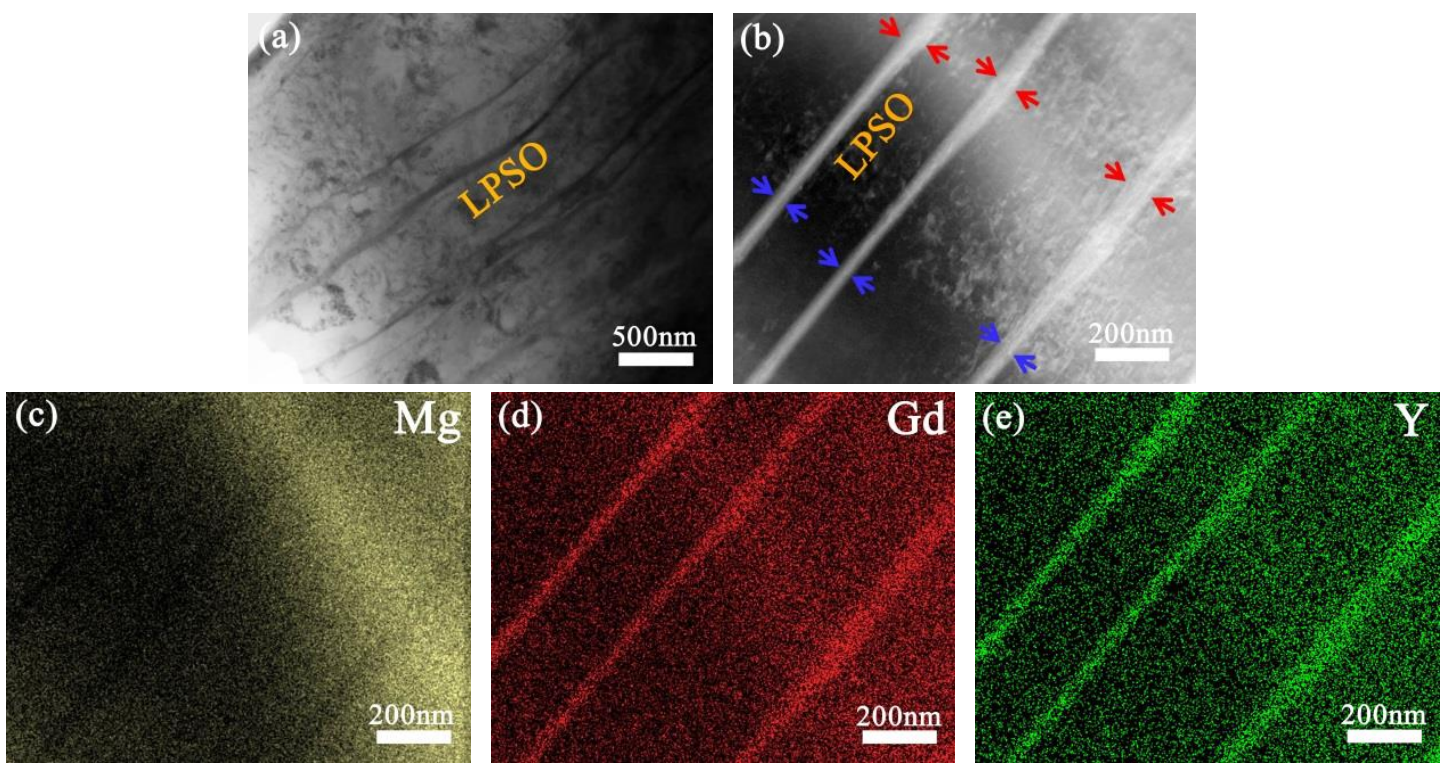


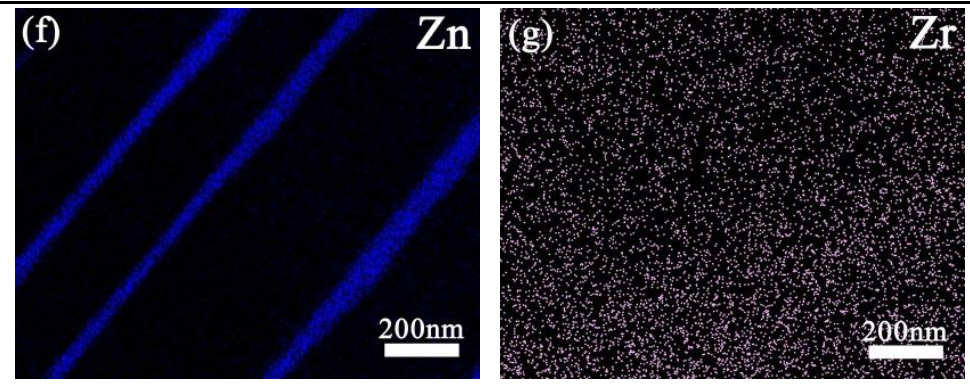

Fig.4 Microstructure of HPT1 ( $\left.\varepsilon_{\mathrm{eq}} \sim 3.4\right)$ : (a) TEM bright-field image; (b) HAADF-STEM image; elemental mappings of (b): (c) Mg; (d) Gd; (e) Y; (f) Zn and (g) Zr.

Fig. 5(a) reveals that after 5 turns the LPSO lamellae are heavily deformed by shear stress and thus not parallel to each other. As shown in Fig. 5(b)-(g), the deformed LPSO lamellae have nonuniform contrast and non-uniform chemical composition, whilst the interfaces of LPSO/Mg matrix are ambiguous in structure. This suggests diffusion of solute atoms across the interfaces into the $\mathrm{Mg}$ matrix aided by the abundant defects created by HPT. At this stage (5 turns of HPT), the fragmented block-shaped LPSO structures have an irregular interface with the matrix (see Fig. 6), which also indicates that the diffusion of solutes into the Mg-rich phase occurs. It is evident from Fig. 5(a) that 5 turns of HPT introduces significant grain refinement with an average grain size of $\sim 120 \mathrm{~nm}$ in the vicinity of LPSO lamellae. While tangled dislocation pileups/cells dominate near the region of the coarse LPSO blocks, the presence of some discrete spots in selected area electron diffraction (SAED) patterns (inset in Fig. 6(b)) confirms the presence of low angle or subgrain boundaries. In comparison with block-shaped LPSO particles, the lamellae are more effective in inducing grain refinement.
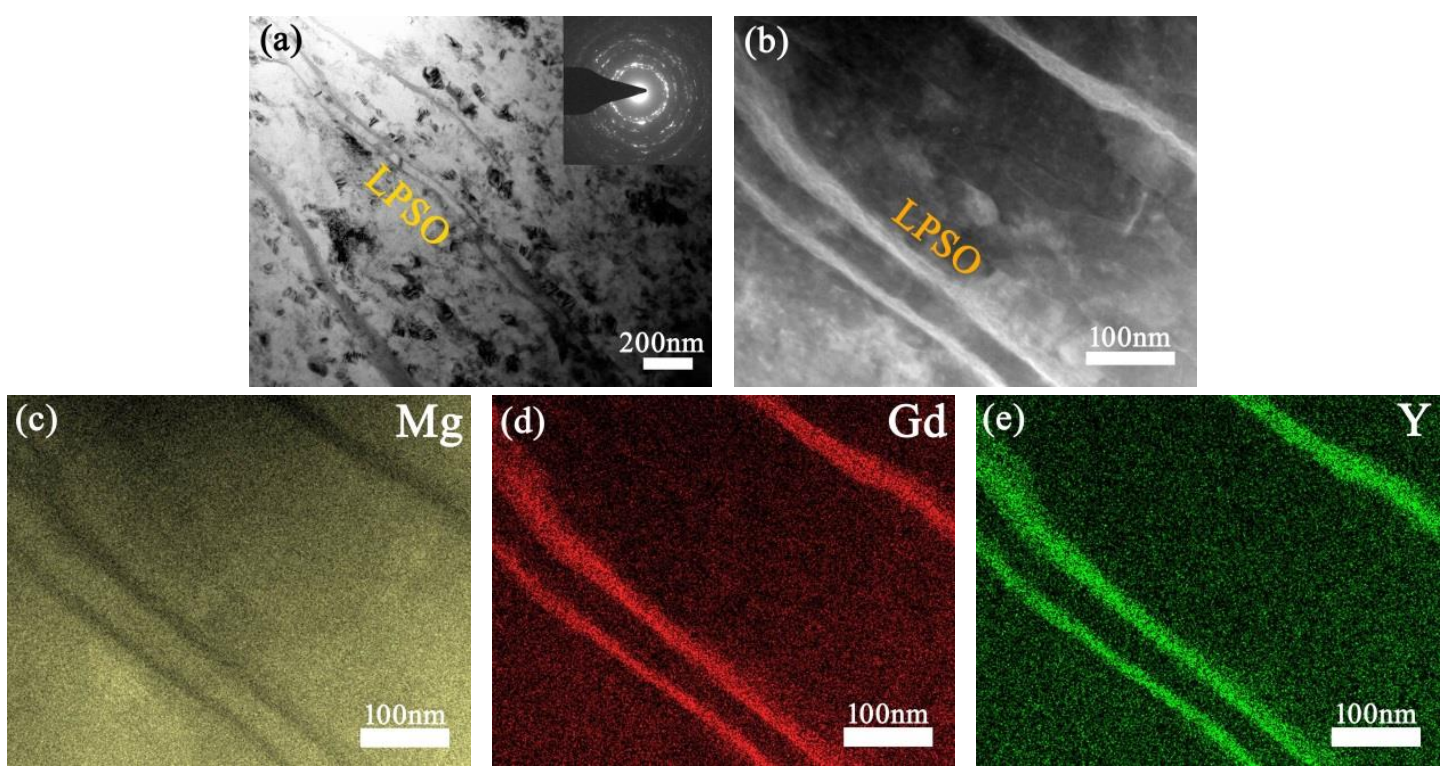


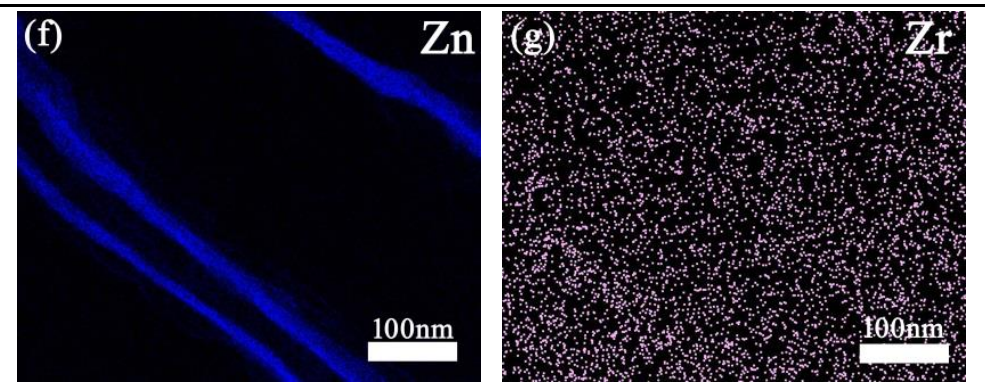

Fig.5 Microstructure of HPT5 ( $\left.\varepsilon_{\mathrm{eq}} \sim 5.2\right)$ : (a) TEM bright-field image of the region near original lamellar-shaped LPSO and corresponding selected area electron diffraction (SAED) patterns; (b) HAADF-STEM image; elemental mappings of (b): (c) Mg; (d) Gd; (e) Y; (f) Zn and (g) Zr.
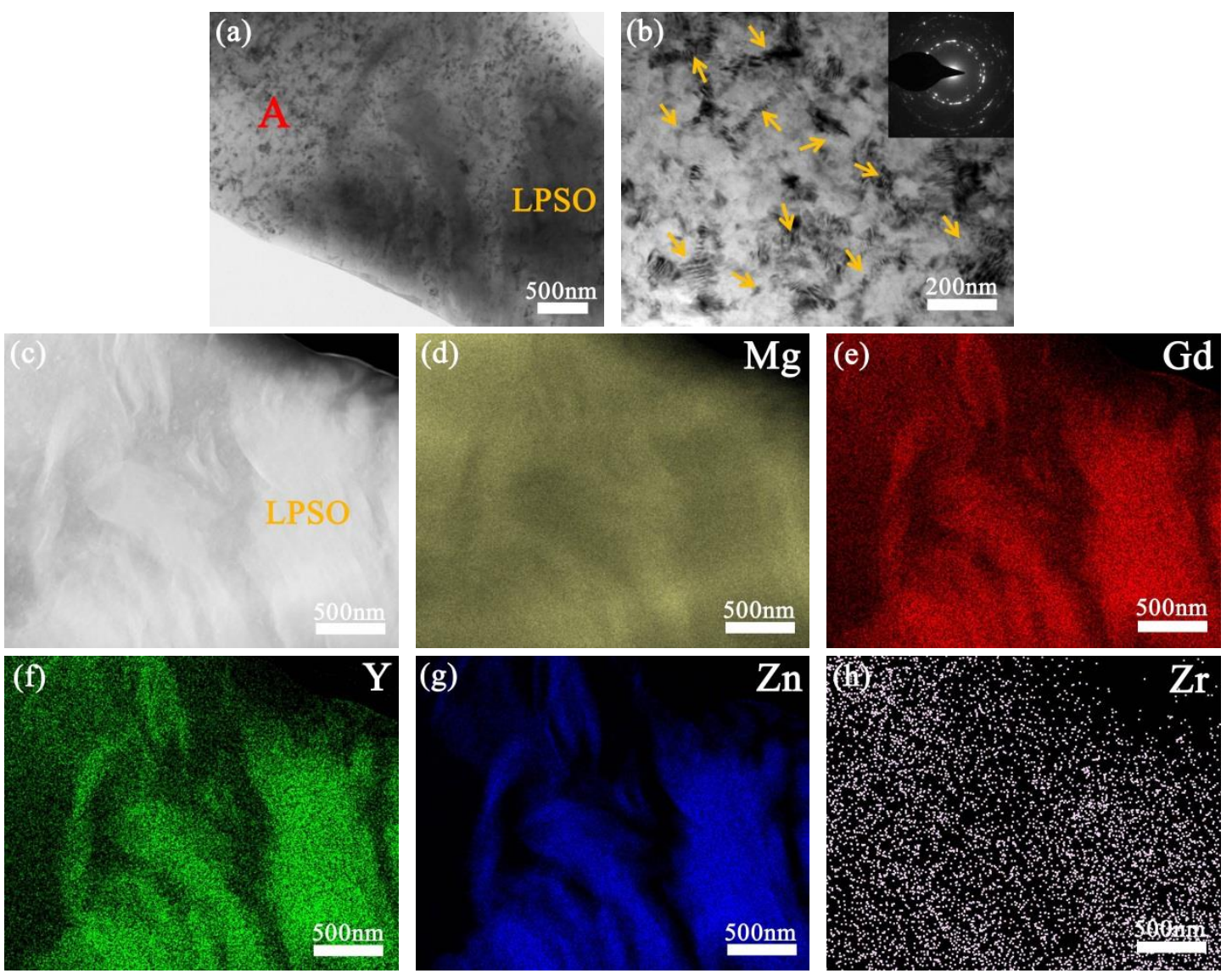

Fig.6 Microstructure of HPT5 ( $\varepsilon_{\text {eq }} \sim$ 5.2): (a) TEM bright-field image of the region near original block-shaped LPSO; (b) high magnification TEM bright-field image acquired from the region A marked in (a) and corresponding SAED patterns; (c) HAADF-STEM image; elemental mappings of (c): (d) Mg; (e) Gd; (f) Y; (g) Zn and (h) Zr.

The microstructure evolution after 10 turns is shown in Fig. 7 and Fig. 8. The above SEM and TEM observations show that at this stage the amount of LPSO lamellae gradually decreases, and the residual LPSO structures can be discriminated by HAADF-STEM due to their bright contrast (see Fig. 7(c)). Compared to the state prior to HPT, the LPSO structures are drastically changed due to HPT for 10 turns (see Fig. 7(c)): they now appear as curved plates with non-uniform bright contrast. The elemental mappings shown in Fig. 7(d)-(h) reveal that the 
distributions of solute atoms are non-uniform. At this stage (after 10 turns), the dislocation pileups/cells near block-shaped LPSO phase observed for lower deformation levels are transformed into nanosized grains (see Fig. 8(a) and (b)), as verified by the ring-like SAED patterns. As seen from Fig. 8(c)-(h) the solute concentration profiles of block- shaped LPSO phase are more uneven and scattered than that of HPT5 (see Fig. 6(c) and Fig. 2), i.e. the decomposition of block-shaped LPSO phase has further progressed (this will ultimately lead to their complete dissolution, see below).
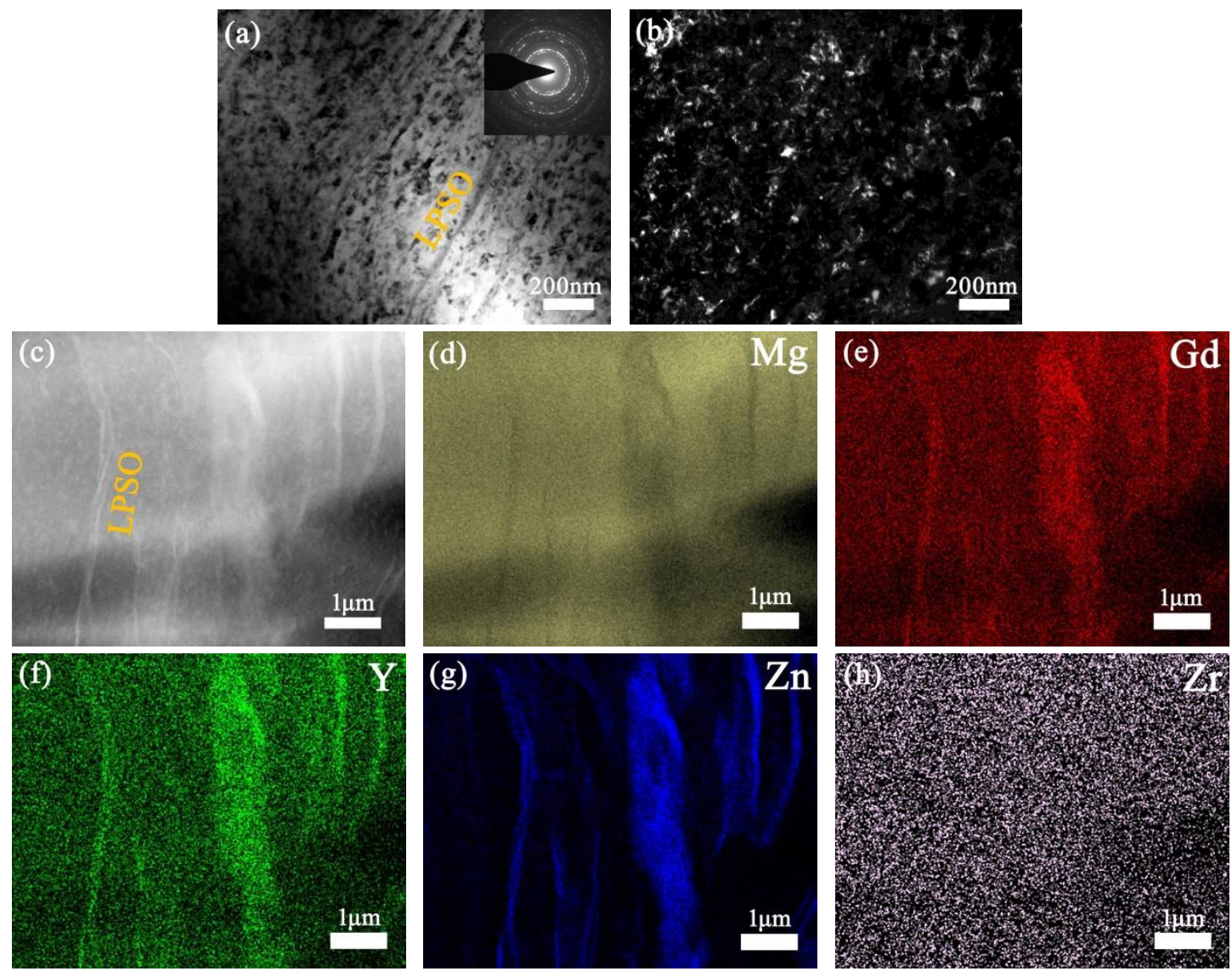

Fig.7 Microstructure of HPT10 ( $\left.\varepsilon_{\mathrm{eq}} \sim 6.0\right)$ : (a) TEM bright-field image of the region near original lamellar-shaped LPSO and corresponding SAED patterns; (b) TEM dark-field image; (c) HAADFSTEM image; elemental mappings of (c): (d) Mg; (e) Gd; (f) Y; (g) Zn and (h) Zr.
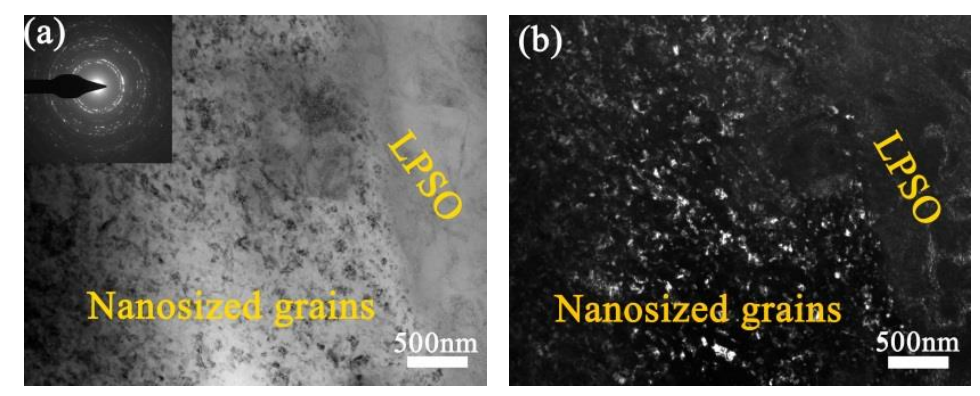


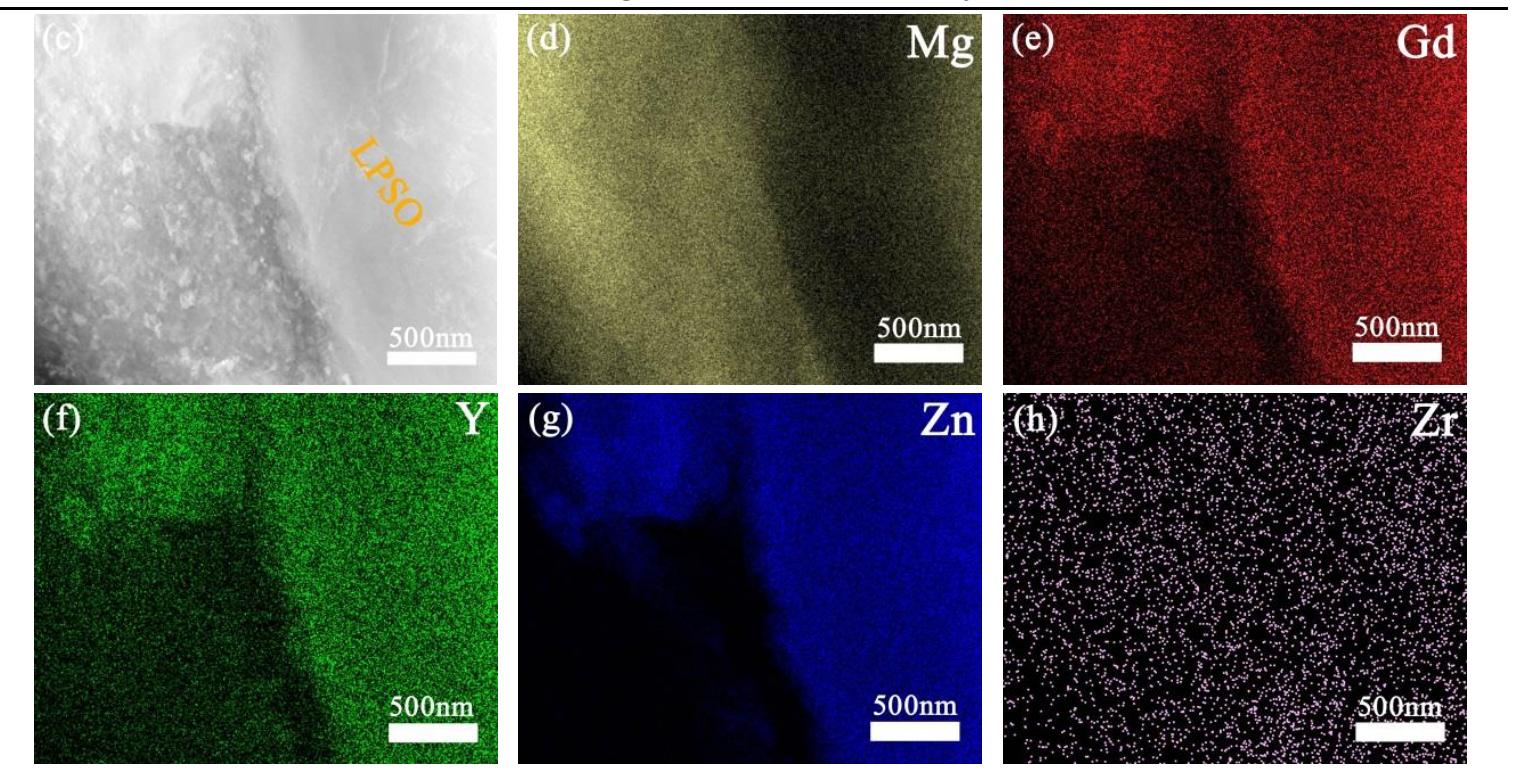

Fig.8 Microstructure of HPT10 ( $\left.\varepsilon_{\mathrm{eq}} \sim 6.0\right)$ : (a) TEM bright-field image of the region near original block-shaped LPSO and corresponding SAED patterns; (b) TEM dark-field image; (c) HAADFSTEM image; elemental mappings of (c): (d) Mg; (e) Gd; (f) Y; (g) Zn and (h) Zr.

After HPT for 16 turns, the sample exhibits almost equiaxed grains with a mean size of $\sim 52$ $\mathrm{nm}$, and corresponding ring-like SAED patterns indicate that the nanograins with high-angle grain boundaries have formed (see Fig. 9). Remarkably, no evidence for the presence of any LPSO phase can be found. The elemental mappings in Fig. 9(c)-(h) show a relatively homogenous solute distribution without any obvious solute aggregation, indicating that the LPSO phase has dissolved into the $\alpha-\mathrm{Mg}$ matrix.

After HPT processing for 20 turns, the sample possesses a uniform nanostructure with homogeneous solute distributions similar to that of HPT16 sample (see Fig.10), indicating that a saturated microstructure can be obtained within 16 turns of HPT. EDS analysis of the Mg matrix in the HPT16 sample which shows a composition of $7.52 \pm 0.05$ wt. $\%$ Gd, $3.43 \pm 0.03$ wt. $\%$ Y, $0.57 \pm$ 0.05 wt. $\% \mathrm{Zn}$. These contents of solutes in the $\alpha$ $\mathrm{Mg}$ matrix are comparable to the equilibrium solubility of solutes at the solid solution temperature of $510{ }^{\circ} \mathrm{C}$ obtained from thermodynamic modelling, and substantially exceeds the equilibrium solubility limit at the HPT processing temperature of $25{ }^{\circ} \mathrm{C}$ (see Fig. 11). These results further show that a supersaturated solid solution is produced by HPT processing at ambient temperature. Throughout all the reported TEM and SEM work no precipitation during HPT deformation is observed.
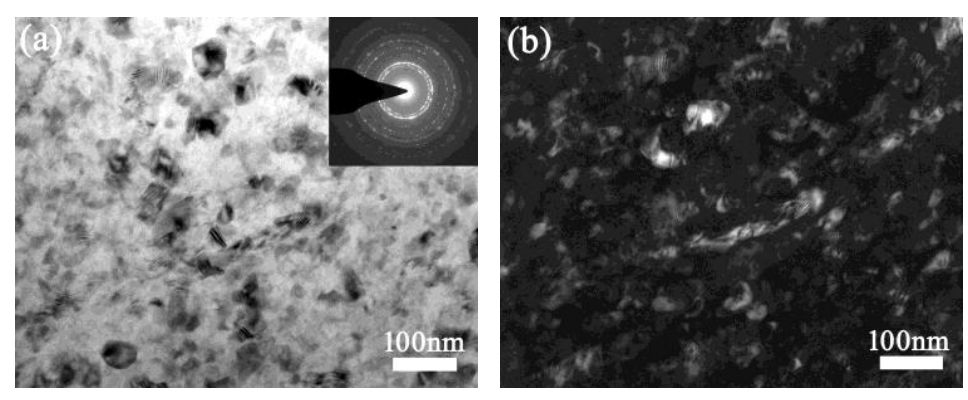


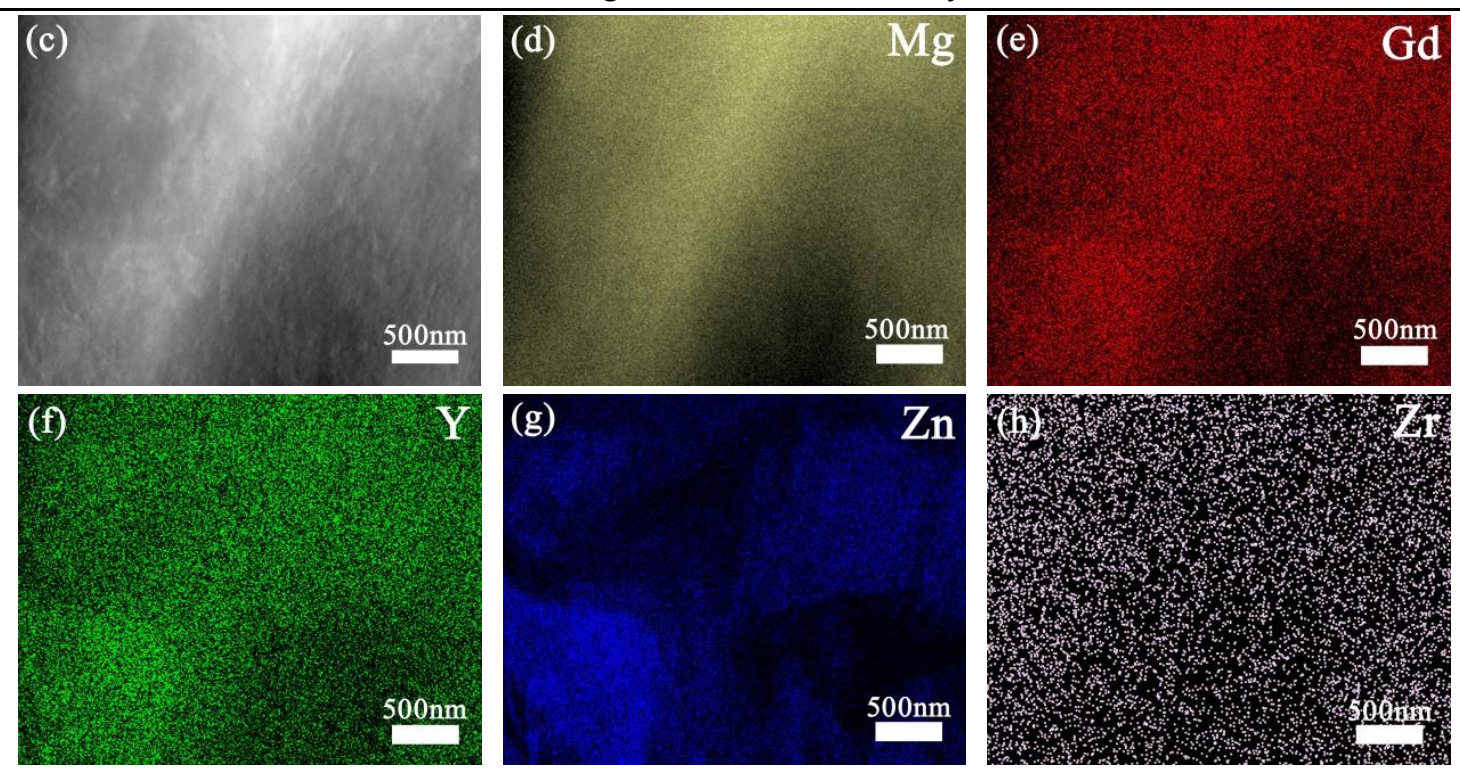

Fig.9 Microstructure of HPT16 ( $\varepsilon_{\mathrm{eq}} \sim 6.6$ ): (a) TEM bright-field image and corresponding SAED patterns; (b) TEM dark-field image; (c) HAADF-STEM image; elemental mappings of (c): (d) Mg; (e) Gd; (f) Y; (g) Zn and (h) Zr.
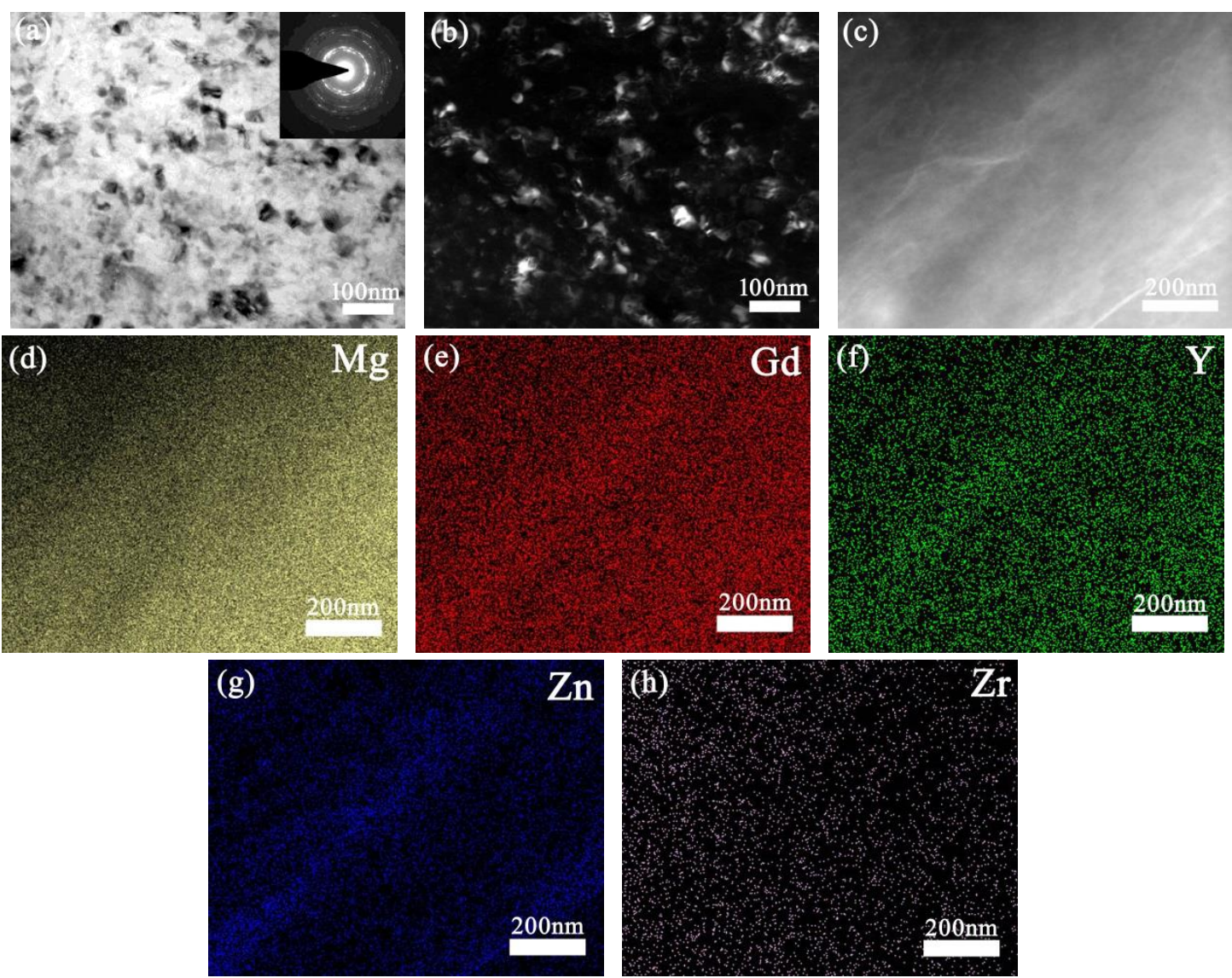

Fig.10 Microstructure of HPT20 ( $\varepsilon_{\mathrm{eq}} \sim 6.8$ ): (a) TEM bright-field image and corresponding SAED patterns; (b) TEM dark-field image; (c) HAADF-STEM image; elemental mappings of (c): (d) Mg; (e) Gd; (f) Y; (g) Zn and (h) Zr. 

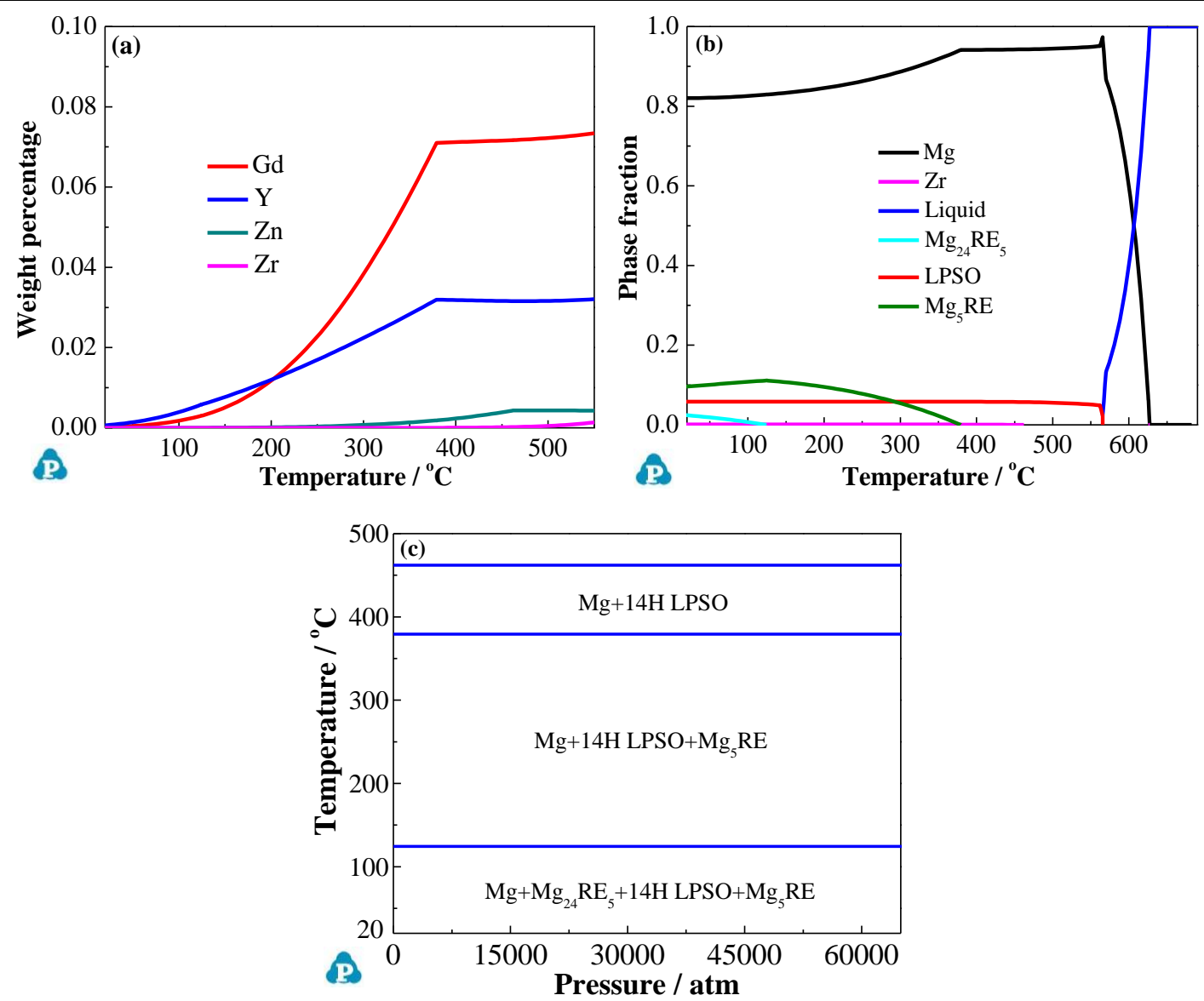

Fig.11 Results of thermodynamic modelling using the PanMg database (a) Variation of solid solubility of solutes with temperature under $1 \mathrm{~atm}$ [43]; (b) Dependence of equilibrium phase fraction on temperature under $1 \mathrm{~atm}$; (c) Pressuretemperature phase diagram of Mg-8.2Gd-3.8Y-1.0Zn-0.4Zr (wt.\%) alloy.

\subsection{XRD analysis}

XRD patterns of the initial state and HPTprocessed $\mathrm{Mg}-\mathrm{Gd}-\mathrm{Y}-\mathrm{Zn}-\mathrm{Zr}$ alloy with various revolutions are presented in Fig. 12. The characteristic peaks marked as solid triangles and circles shown in Fig. 12(a) are identified as $14 \mathrm{H}$ LPSO phase and $\mathrm{Mg}$ phase according to the PDF file Card 36-1273 and PDF file Card 35-0821, respectively [44]. The initial (pre-HPT) sample consists of $\alpha-\mathrm{Mg}$ phase and LPSO phase. With increasing HPT turns from $1 / 8$ to 20 , the width of LPSO phase diffraction peaks initially becomes broader and their intensity becomes weaker, and eventually the peaks due to LPSO phase completely disappear, which is associated with the disordering and dissolution of LPSO phase structures (lamellae and blocky particles) during HPT deformation. As shown in Fig. 12(b), the diffraction peaks of the $\alpha-\mathrm{Mg}$ phase matrix shift toward lower angles with increasing deformation, indicating that the lattice parameters increase due to increased content of alloying elements in the $\alpha$ Mg phase crystal lattice [21, 43]. This observation and the absence of any second phase peaks (LPSO or otherwise) provided further confirmation that a supersaturated solid solution is formed. The substantial broadening of the $\mathrm{Mg}$ peaks on progression of HPT deformation indicates that the processing causes considerable structural refinement and microstrains [33, 39, 43, 45]. 

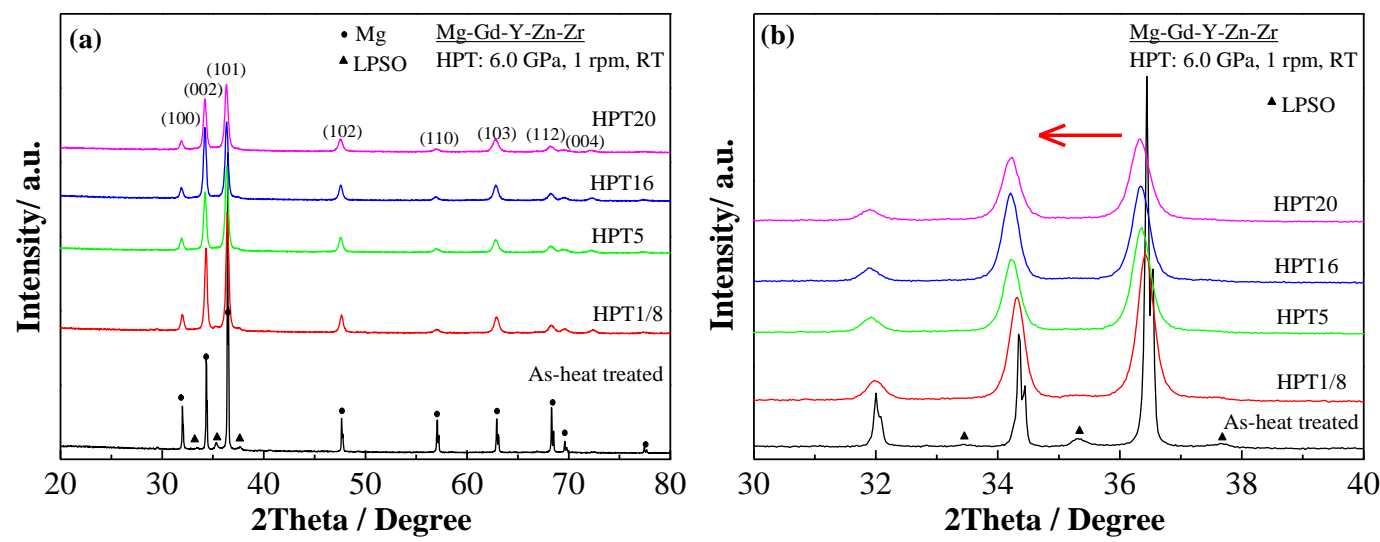

Fig. 12 (a) Overview of XRD patterns of the as-heat treated and HPT-processed Mg-Gd-Y-Zn-Zr material with various HPT revolutions; (b) section of the XRD patterns showing line broadening and the red arrow indicates the shift direction of the Mg peaks.

The crystallite size, microstrains, dislocation density and lattice axial ratio $c / a$ of the $\alpha-\mathrm{Mg}$ phase for HPT-processed samples determined from the XRD patterns are listed in Table 1. It can be seen that the dislocation density increases rapidly with the number of HPT turns to reach $\sim 5.0 \times 10^{14} \mathrm{~m}^{-2}$ after 20 turns, which is much larger than that reported for other HPT-deformed $\mathrm{Mg}$ alloys with a lower amount of LPSO structures [21, 43, 46, 47]. This rapid increase to a high dislocation density is thought to be due to three main factors. Firstly, the presence of the LPSO lamellae causes mechanical inhomogeneity and anisotropy, i.e. grains are effectively composite materials each with a different orientation. This induces an inhomogeneous strain which enhances dislocation generation and particularly kink bands results in additional dislocations around the interface of LPSO/Mg matrix. Secondly, before they dissolve, the LPSO lamellae effectively hinder dislocation motion and thus limit recovery. Thirdly, when LPSO lamellae have dissolved the high solute content in the matrix further contributes to retardation of dislocation annihilation through the enhanced solute- dislocation and / or dislocation-dislocation interaction [43].

The crystallite sizes estimated from XRD line broadening analysis are slightly smaller than those measured by TEM observations, because the former represents the coherent diffraction domain size that is related to the subgrain or dislocation cell size $[33,48]$ whereas the latter is obtained by the linear intercept method [31-33]. The lattice axial ratio $c / a$ of the Mg-rich hexagonal closedpacked (HCP) phase can be used to evaluate the degree of lattice distortion induced by solute atoms [49]: both first-principles calculations and experiments [50-52] indicate that $c / a$ decreases with increase of RE solutes in the Mg-rich phase. The measured $c / a$ of our HPT-processed samples is smaller than that of pure $\mathrm{Mg}$ (1.623) and reduces with increasing HPT deformation, with $c / a$ for the HPT20 sample being quite similar to that of the Mg-Gd-Y-Zn-Zr supersaturated solid solution prepared by HPT starting from an assolid solution treated condition [43]. These observations indicate that the concentration of RE solute atoms in the $\mathrm{Mg}$-rich phase increases due to the HPT-induced LPSO decomposition. 
Table 1 the crystallite size, microstrains, dislocation density and lattice axial ratio $c / a$ of HPT-processed Mg-Gd-Y-ZnZr alloy with various revolutions

\begin{tabular}{ccccc}
\hline Samples & $\begin{array}{c}\text { Crystallite size } \\
D_{c}(\mathrm{~nm})\end{array}$ & $\begin{array}{c}\text { Microstrains } \\
\varepsilon(\%)\end{array}$ & $\begin{array}{c}\text { Dislocation density } \rho \\
\left(\times 10^{14} \mathrm{~m}^{-2}\right)\end{array}$ & $\begin{array}{c}\text { Lattice axial } \\
\text { ratio } c / a\end{array}$ \\
\hline HPT1/8 & 92.2 & 0.143 & 1.68 & 1.6215 \\
HPT5 & 63.0 & 0.167 & 3.27 & 1.6189 \\
HPT16 & 50.4 & 0.216 & 4.73 & 1.6159 \\
HPT20 & 49.5 & 0.232 & 5.06 & 1.6137 \\
\hline
\end{tabular}

\subsection{Microhardness evolution}

Fig. 13(a) shows the evolution of microhardness across the diameter of HPTprocessed disks with various revolutions. All the values of microhardness are increased after HPT processing. For samples deformed up to 10 turns the microhardness increases with the distance from centre toward the periphery, as the strains increase with the radius direction. With further
HPT turns up to 16 and 20, except for a slight low microhardness at centre, the hardness distribution along diameter become quite uniform. The dependence of microhardness on the equivalent strain plotted in Fig. 13(b) reveals the microhardness substantially increases up to $128 \pm 2$ $\mathrm{HV}$ at an equivalent strain of $\sim 6.6$, but further straining does not bring about obvious change, i.e. a statured condition is reached.
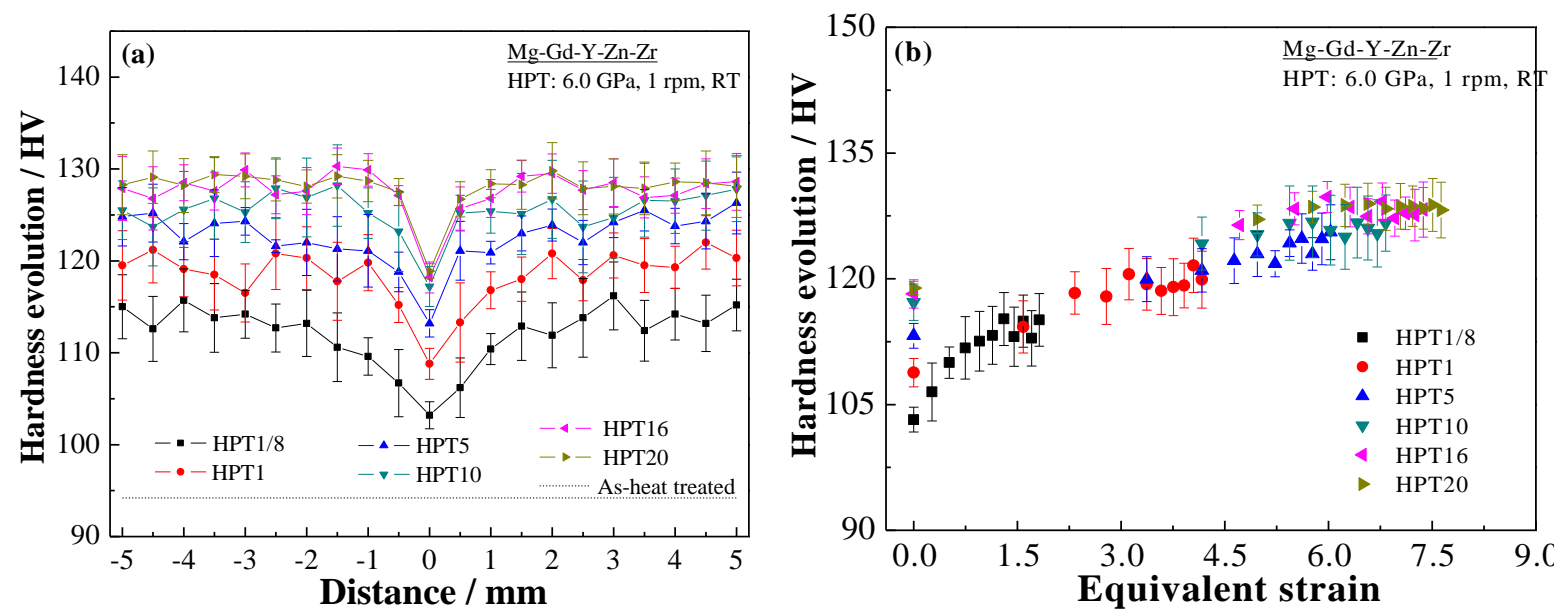

Fig.13 (a) Vickers microhardness measured across the diameter of HPT-processed Mg-Gd-Y-Zn-Zr disks with different HPT revolutions (the dashed line represents the microhardness of initial heat-treated alloy); (b) Vickers microhardness as a function of equivalent strain. 


\section{Discussion}

\subsection{The deformation, fragmenting and} decomposition of LPSO structures

To better understand the evolution of microstructure during HPT processing, a schematic illustration of the main stages is presented in Fig.14. In the first stage $\left(\varepsilon_{\mathrm{eq}} \leqslant 3.4\right)$ the grain size is similar to that of the initial heattreated sample. The block-shaped LPSO phase particles are relative stable, whereas kink banding and solute diffusion occur in the LPSO lamellae. The line broadening observed for the peaks of the LPSO phase in the XRD spectra indicate that the initial HPT deformation has induced a substantial density of dislocations in the LPSO phase particles. During the second stage $\left(5.2 \leqslant \varepsilon_{\mathrm{eq}} \leqslant 6.0\right)$, two types of grain evolution are established. Firstly, nanoscale grains are formed around the LPSO lamellae, which are deformed and broken up at the position of bending caused by kink bands. This is ascribed to dislocation pile up in the vicinity of the kink boundaries which provides the energy for the activation of grain refinement [19]. A second type of grain refinement is seen at blockshaped LPSO particles which fragment due to the HPT straining, while dense dislocation pileups/cells appear near the fragmented blockshaped LPSO phase. These cellular structures are transformed into nanocrystalline grains with large-angle misorientations during the third stage $\left(6.6 \leqslant \varepsilon_{\text {eq }} \leqslant 6.8\right)$. When sufficient large strains are imposed, a uniform nanostructure with a mean grain size of approximately $52 \mathrm{~nm}$ is achieved, and the LPSO phase decomposes to form a stable supersaturated solid solution. As reported, the pressure of the boundaries on the second phases can provide the energy for their dissolution [12] The strain accumulated at the boundaries increases with equivalent strain, thus providing additional energy for the dissolution process. It is noted that the microstructure refinement near the lamellar-shaped LPSO phase develops more rapidly than that near the block-shaped ones (see Fig. 5-Fig. 8). In general terms this can be explained by the fact that the lamellae are more effective in blocking dislocation movement and in causing local accumulation of dislocations, due them intersecting slip planes at a higher density, i.e. causing more obstacles [32]. At the nanoscale, the presence of kink banding in LPSO lamellae not only induces more additional defects at the boundaries of kink bands, but also favors the dislocation accumulation by effectively hindering their motion. The higher dislocation density in the vicinity of deformed lamellar structures promotes recovery and recrystallization, accelerating the grain refinement. 


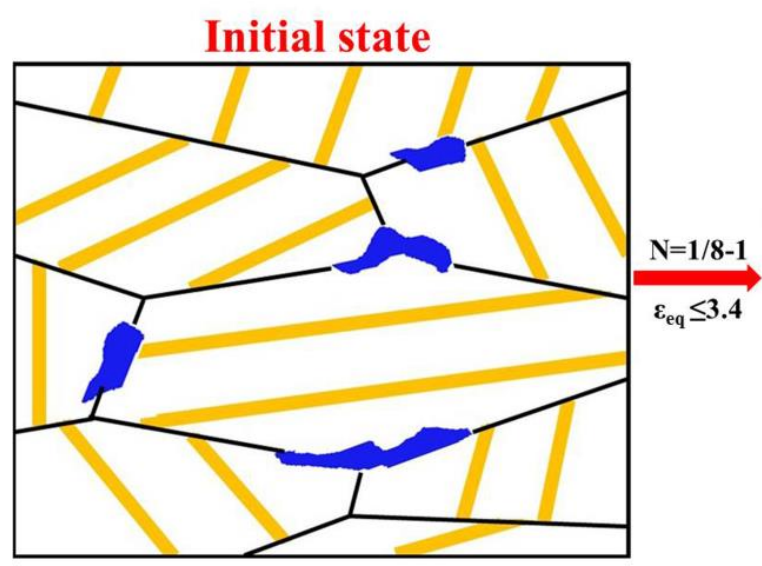

Third stage
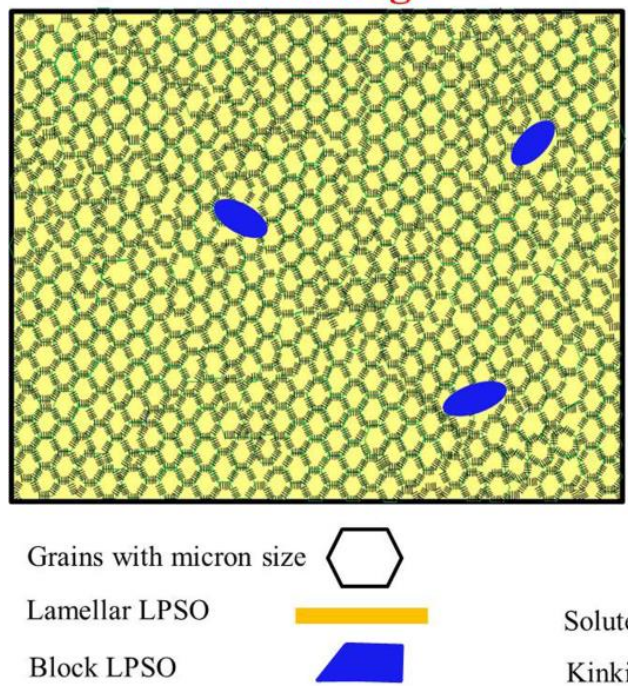

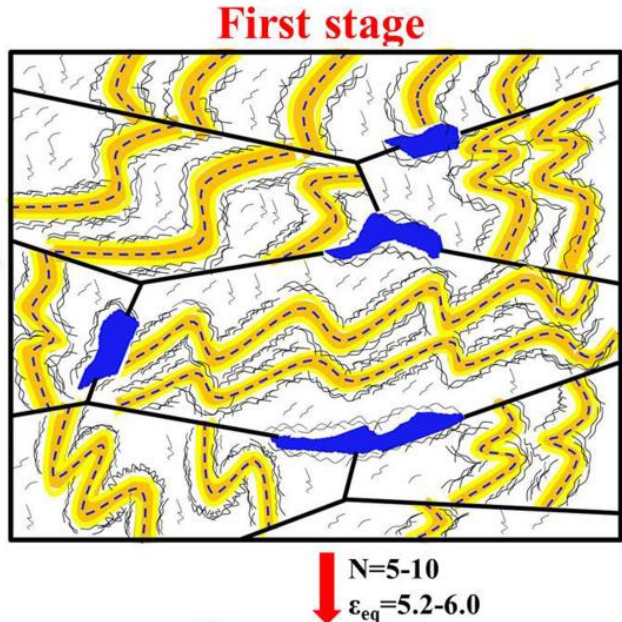

Second stage

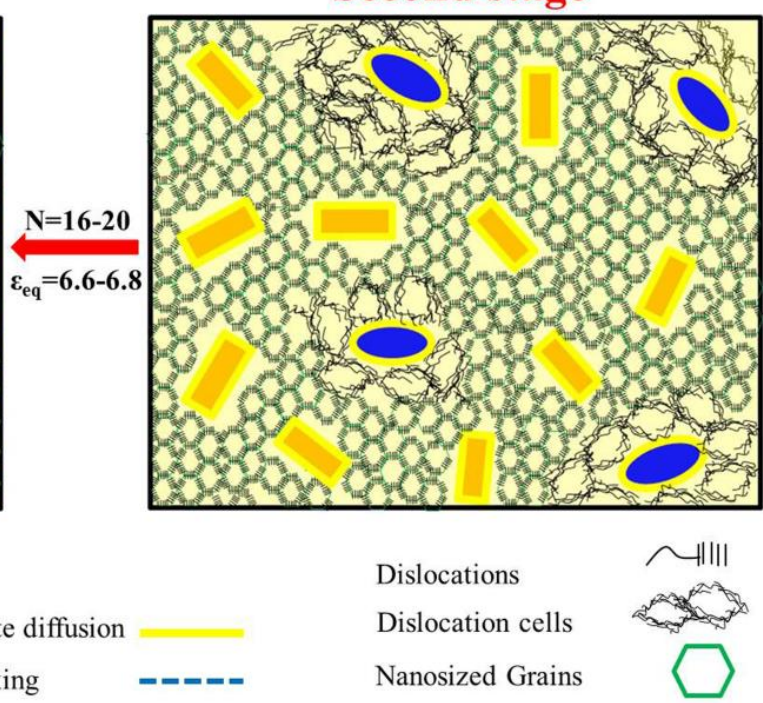

Fig. 14 Schematic illustration of microstructure evolution of LPSO-containing Mg-Gd-Y-Zn-Zr alloy at different stages during HPT processing.

The thermodynamic modelling presented in Fig. 11 indicates that the $14 \mathrm{H}$ LPSO phase is a stable phase at room temperature and remains stable, with very little dissolution, on increasing the temperature to $550{ }^{\circ} \mathrm{C}$. Furthermore, it seems that pressure does not influence the phase diagram significantly as shown Fig. 11(c). In line with this, it has been shown that in a $\mathrm{Mg}_{85} \mathrm{Zn}_{6} \mathrm{Y}_{9}$ alloy the $10 \mathrm{H}$ - and 18R-type LPSO were stable below 400 ${ }^{\circ} \mathrm{C}$ under $3 \mathrm{GPa}$ [53]. However, the present research indicates that HPT induces the dissolution of LPSO phase at ambient temperature. It is thought that the high density of defects generated by HPT is causing this dissolution. HPT processing introduces abundant defects such as dislocations and grain boundaries both in the LPSO phase and the $\alpha-\mathrm{Mg}$ phase, which will modify the free energy of these phases, for instance by providing energetically favourable sites for RE atoms to locate at defects in the $\alpha-\mathrm{Mg}$ phase (at grain boundaries, dislocations or vacancies). Continuously increasing shear in the LPSO phase caused by movement of dislocations in them will disrupt the ordering and thus increase the free energy of the LPSO phase. Further, the TEM has shown that HPT processing causes the 
surface to volume ratio of the LPSO lamellae and particles to increase due to deformation and fracturing. This will cause an increase in the total free energy associated with LPSO lamellae and particles (i.e. the volume free energy plus the interface free energy), and as a result they will become less stable (this is the so-called GibbsThomson effect [21]). As the unstable LPSO lamellae and particles start to dissolve, the dislocations will provide rapid diffusion channels during deformation [24], which will increase dissolution rates. These suggestions are consistent with XRD data which show line broadening for the LPSO phase and the TEM observations (see Fig.3-Fig.10), which show element contrast at the blurry interface of LPSO/Mg matrix suggesting that LPSO particles/lamellae are decomposing at areas of high dislocation density, potentially aided by dislocation movement. As a further support of these interpretations it is noted that annealing of 20 turns HPT-processed sample at $400{ }^{\circ} \mathrm{C}$ for $1 \mathrm{~h}$, which allows for defect annealing and high diffusion rates, LPSO phase reforms (See supporting material).

It is noteworthy that the evolution of LPSO lamellae and particles during the present HPT deformation at room temperature is quite different from that observed in published work on SPD processing of $\mathrm{Mg}-\mathrm{RE}$ type alloys at $300-500^{\circ} \mathrm{C}$, as these works all show LPSO phase to be present after processing. For instance, FSP of as-cast $\mathrm{Mg}$ 9.4Gd-4.1Y-1.2Zn-0.4Zr (wt.\%) containing LPSO at $500{ }^{\circ} \mathrm{C}$ resulted in breakup and complete dissolution of original 18R LPSO particles at the grain boundaries, and meanwhile fine poly types of $18 \mathrm{R}$ and $24 \mathrm{R}$ LPSO lamellae with a width of $\sim 5$ to $\sim 200 \mathrm{~nm}$ precipitated from the matrix and were distributed within the grains [9]. ECAP processing modified the LPSO distribution by deforming and fracturing the LPSO structures, with final sizes and distributions depending on the processing strain and temperature [54]. During ECAP of Mg$1.0 \mathrm{Zn}-1.8 \mathrm{Gd}-0.1 \mathrm{Zr}$ (at.\%) alloy up to 16 passes at $375{ }^{\circ} \mathrm{C}[55,56]$, the $\beta$ phase that was initially present gradually dissolved and lamella-shaped 14H LPSO phase precipitated. The lamellae were then bent to a large angle, and cracks initiated along the shear planes, leading to the formation of numerous fine 14H LPSO microcells with a width of 0.25-0.5 $\mu \mathrm{m}$ and a length of 0.5-1.5 $\mu \mathrm{m}$. During ECAP processing of both an as-cast and an asextruded Mg-2Y-1Zn (at.\%) alloy at $300{ }^{\circ} \mathrm{C}$ and $350{ }^{\circ} \mathrm{C}$ the $18 \mathrm{R}$ LPSO plates were fragmented into small particles with a mean size of $\sim 10 \mu \mathrm{m}$ [54], and the work indicated that the fragmentation of LPSO phase and grain refinement were more pronounced when processed at higher strains and lower temperature.

A further difference between the present HPT processing at room temperature and the above-mentioned works on SPD processing at $300-500{ }^{\circ} \mathrm{C}$ is the much stronger grain refinement observed achieved in our work. Thus the present processing provides a $\mathrm{Mg}$ alloy with a uniquely refined nanostructure with high dislocation density as well as complete dissolution of the LPSO particles.

\subsection{Hardening produced by HPT}

In order to elucidate the effect of initial profuse LPSO phase on hardening in the present Mg-Gd-Y-Zn-Zr alloy, a comparison of hardness evolution during HPT of this alloy with different starting microstructure is provided in the doublenatural logarithmic plots of microhardness against equivalent strains in Fig. 15. As shown in Fig. 15(a), the hardness obtained in present case is larger than that obtained by HPT processing of the same alloy in an as-cast condition [21], but it is 
similar to that obtained by HPT processing of the same alloy in a solution-treated condition [43]. In Fig. 15(b), the solid line of the present HPTprocessed alloy exhibits a relationship of $H V \approx 113 \mathrm{HV} \times \varepsilon^{0.07}$. Thus the hardening exponent is about 0.07 , which compares to $\sim 0.05$ and $\sim 0.09$ for HPT of the as-cast and the solutionized Mg8.2Gd-3.8Y-1.0Zn-0.4Zr (wt.\%) materials, respectively [43]. For HPT processing of the ascast and the solutionized samples, the microstructure refinement reached a saturated state at $\varepsilon_{\mathrm{eq}} \sim 6.0$. By comparison, higher torsional strain is required to achieve the steady state $\left(\varepsilon_{\text {eq }} \sim 6.6\right)$ in the alloy containing large amount of

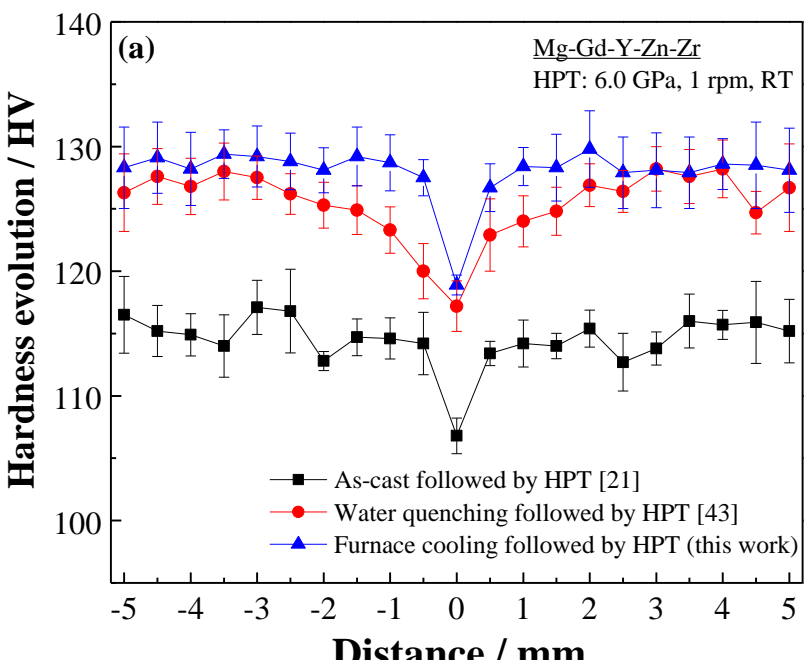

Fig.15 (a) Comparison of hardness evolution after HPT of different starting materials; (b) Double-natural logarithmic plot of hardness values vs. equivalent strains for different initial states followed by HPT processing.

The present analysis shows that the saturated hardness of a HPT-processed Mg alloy containing LPSO structures can be increased by modifying microstructural factors, mainly including (i) the pronounced grain refinement, (ii) the enhanced dislocation density, (iii) the increment of solid solutes originating from the decomposition of LPSO phase and (iv) reduced residual LPSO particles. Amongst these contributing factors, the

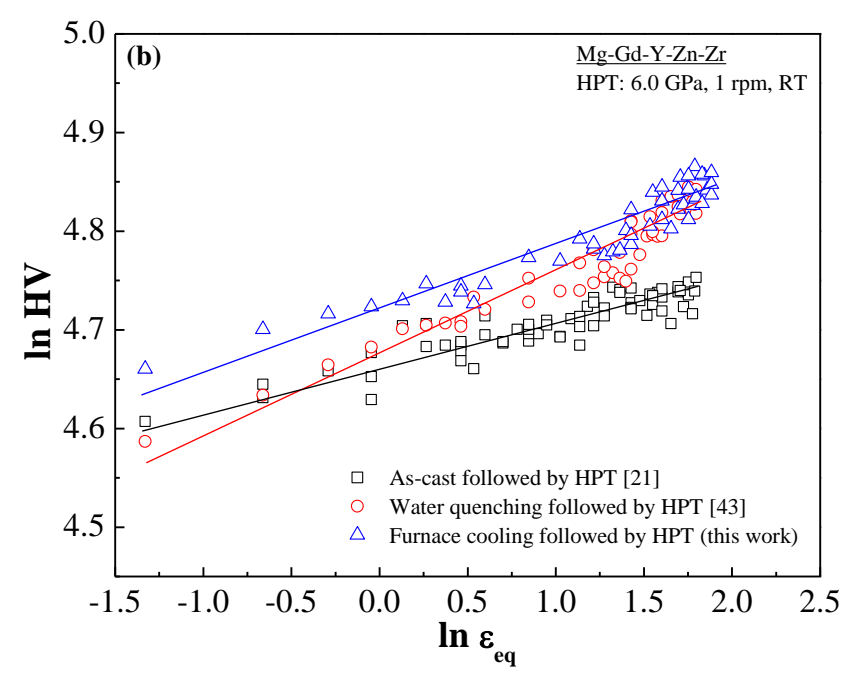

LPSO lamellae, which is thought to be due to the large amount of LPSO/ $\alpha-\mathrm{Mg}$ interfaces hindering dislocation motion [21, 43]. With increasing HPT turns, decomposition of LPSO phase lamellae leads to an increased concentration of solute atoms in the $\alpha-\mathrm{Mg}$ matrix, which hinder the dislocation movement by the solute drag effect. This explains why the present exponent (0.07) is higher than that of the same as-cast alloy deformed by HPT. In addition, the saturated hardness of the present alloy is similar to that of the as-solutionized alloy processed by HPT (Fig. 15(b)), but the latter has a faster hardening rate due to the more rapid occurrence of refinement.

hardening effect of residual particles is generally limited due to large inter-particle spacing of remnants.

The contributions from the various strengthening mechanisms will be quantitatively discussed. Due to the small sample size only hardness could be reliably obtained (yield strength measurement was not attempted), and hence in this analysis the yield strength increment was 
predicted, and hardness $H V$ was estimated from the yield strength $\sigma_{\mathrm{y}}$ using the relationship of $H V=\mathrm{C} \sigma_{\mathrm{y}}$, where $\mathrm{C}$ is a constant about $\sim 0.3$ HV/MPa [33, 57].

Firstly, to identify the influence of grain refinement on the yield strength, the Hall-Petch relationship $\Delta \sigma_{G B}=k_{H P} d^{-1 / 2}[33,57,58]$ is used, where $k_{H P}$ is the Hall-Petch constant of 40.7 $\mathrm{MPa} \cdot \mu \mathrm{m}^{1 / 2}$ taken from the assessment in [57], and $d$ represents the average grain size, taken as $\sim 52 \mathrm{~nm}$. This provides grain boundary strengthening amounts to $\sim 53 \mathrm{HV}$.

Dislocation strengthening can be described by $\Delta \sigma_{\text {dis }}=M \alpha_{1} G b \sqrt{\rho}[33,57,59]$, where $M$ is Taylor factor with 2.6, $\alpha_{1}$ is the dislocation interaction factor with $0.3, G$ is the shear modulus of $17.7 \mathrm{GPa}$ and $b$ is Burgers vector taken as $0.3197 \mathrm{~nm}$ [57]. We measured $\rho=5.06 \times 10^{14} \mathrm{~m}^{-2}$ (Table 1), which provides a hardness increment of $\sim 30 \mathrm{HV}$.

The solid solution strengthening can be estimated as $\Delta \sigma_{S S}=\left(\sum k_{i}^{1 / n} c_{i}\right)^{n}$ [60], where

\section{Conclusions}

In this study, a Mg-Gd-Y-Zn-Zr alloy containing long period stacking ordered (LPSO) phase was subjected to HPT processing at ambient temperature. The evolutions of grain refinement and LPSO structure were systematically investigated, and the hardening mechanisms were also analyzed. The conclusions are summarized as follows:

1. Unlike other thermomechanical processing of LPSO containing Mg alloys, the present HPT processing causes the LPSO lamellae $c_{i}$ are the concentrations of the solute atoms retained in matrix, $n$ is a constant, which for $\mathrm{Mg}$ Gd-Y alloys has been reported to equal 1/2 [60], and $k_{i}$ are 737, 683 and $578 \mathrm{MPa} \cdot(\text { at. } \%)^{-1 / 2}$ for $\mathrm{Y}$, $\mathrm{Gd}$ and $\mathrm{Zn}$, respectively [60]. The values of $c_{i}$ are determined from the EDS results, providing hardening from the increased solute content in matrix is $\sim 33 \mathrm{HV}$.

The total hardness can be expressed as a linear summation of all the contributions assessed above: $\quad H V=H V_{0}+\Delta H V_{G B}+\Delta H V_{\text {dis }}+\Delta$ $H V_{S S}$, in which $H V_{0}$ is the microhardness of pure $\mathrm{Mg}$ in the annealed state before HPT processing ( $6 \mathrm{HV}$ [57]). We can thus see that the calculated hardness in the above simple model is $122 \mathrm{HV}$ which can nearly explain the measured $128 \pm 2 \mathrm{HV}$. Thus the correspondence between modelled strength and measure is very good, and the remaining difference might be due to some limited clustering of solute atoms, or grain boundary segregation, which can increase yield strength. (Or the small difference could be due to measurement uncertainty in the factors that determine the yield strength model.).

to progressively kink, break and dissolve into the matrix, and finally a supersaturated solid solution is formed. Thermodynamic modelling suggests that the pressure caused by HPT in itself does not cause the destabilizing of the LPSO phase, and instead the high dislocations of defects of $5 \times 10^{14}$ $\mathrm{m}^{-2}$ introduced due to the high shear deformation are suggested to cause the driving force for dissolution. The rapid atomic diffusion induced by numerous dislocations contributed to the redistribution of solute atoms resulting from the decomposition of LPSO structure.

2. The evolution of LPSO phase influences 
the microstructure refinement. Due to additional dislocations accumulated by the formation of kink bands in LPSO lamellae, the grain refinement occurs preferentially in the vicinity of lamellarshaped LPSO structures. After the equivalent strain reaches about $\sim 6.6$, a homogenized microstructure with a mean grain size of $52 \pm 2 \mathrm{~nm}$ is achieved.

3. The hardness increases with increasing strain, and reaches a saturated value of $128 \pm 2 \mathrm{HV}$ at an equivalent strain of $\sim 6.6$. Grain boundary strengthening, dislocation strengthening, and

\section{References}

[1] Z. Yang, J.P. Li, J.X. Zhang, G.W. Lorimer, J. Robson, Review on research and development of magnesium alloys, Acta Metal. Sin-Engl. 21 (2008) 313328.

[2] S.H. You, Y.D. Huang, K.U. Kainer, N. Hort, Recent research and developments on wrought magnesium alloys, J. Magn. Alloys 5 (2017) 239-253.

[3] I.H. Jung, M. Sanjari, J. Kim, S. Yue, Role of RE in the deformation and recrystallization of $\mathrm{Mg}$ alloy and a new alloy design concept for Mg-RE alloys, Scr. Mater. 102 (2015) 1-6.

[4] D.K. Xu, E.H. Han, Y.B. Xu, Effect of long-period stacking ordered phase on microstructure, mechanical property and corrosion resistance of $\mathrm{Mg}$ alloys: A review, Prog. Nat. Sci. Mater. Int. 26 (2016) 117-128.

[5] D. Egusa, E. Abe, The structure of long period stacking/order Mg-Zn-RE phases with extended nonstoichiometry ranges, Acta Mater. 60 (2012) 166-178.

[6] F.M. Lu, A.B. Ma, J.H. Jiang, D.H. Yang, Q. Zhou, Review on long-period stacking-ordered structures in Mg-Zn-RE alloys, Rare Met. 31 (2012) 303-310.

[7] W.J. Ding, Y.J. Wu, L.M. Peng, X.Q. Zeng, G.Y. Yuan, Formation of 14H-type long period stacking ordered structure in the as-cast and solid solution treated Mg-Gd-Zn-Zr alloys, J. Mater. Res. 24 (2009) 1842-1854. [8] L. Zheng, C.M. Liu, Y.C. Wan, P.W. Yang, X. Shu, Microstructures and mechanical properties of Mg-10Gd6Y-2Zn-0.6Zr (wt.\%) alloy, J. Alloys Compd. 509 (2011) 8832-8839.

[9] Q. Yang, B.L. Xiao, D. Wang, M.Y. Zheng, K. Wu, Z.Y. Ma, Formation of long-period stacking ordered phase only within grains in $\mathrm{Mg}-\mathrm{Gd}-\mathrm{Y}-\mathrm{Zn}-\mathrm{Zr}$ casting by friction stir processing, J. Alloys Compd. 581 (2013) 585-589. solid solution strengthening are the main strengthening mechanisms, which contribute to a hardness increment of $\sim 53 \mathrm{HV}, \sim 30$ and $\sim 33 \mathrm{HV}$, respectively.

\section{Acknowledgements}

This work was supported by National Key Research and Development Program of China (No. 2016YFB0301102) and National Natural Science Foundation of China (No. 51571068 and $51771062)$.

[10] X.J. Zhou, C.M. Liu, Y.H. Gao, S.N. Jiang, W.H. Liu, L.W. Lu, Microstructure and mechanical properties of extruded Mg-Gd-Y-Zn-Zr alloys filled with intragranular LPSO phases, Mater. Charact. 135 (2018) 76-83.

[11] C. Xu, M.Y. Zheng, K. Wu, E.D. Wang, G.H. Fan, S.W. Xu, S. Kamado, X.D. Liu, G.J. Wang, X.Y. Lv, Effect of cooling rate on the microstructure evolution and mechanical properties of homogenized Mg-Gd-Y-Zn-Zr alloy, Mater. Sci. Eng. A 559 (2013) 364-370.

[12] C. Xu, M.Y. Zheng, K. Wu, E.D. Wang, G.H. Fan, S.W. Xu, S. Kamado, X.D. Liu, G.J. Wang, X.Y. Lv, M.J. Li, Y.T. Liu, Effect of final rolling reduction on the microstructure and mechanical properties of Mg-Gd-YZn-Zr alloy sheets, Mater. Sci. Eng. A 559 (2013) 232240.

[13] C. Xu, S.W. Xu, M.Y. Zheng, K. Wu, E.D. Wang, S. Kamado, G.J. Wang, X.Y. Lv. Microstructures and mechanical properties of high-strength Mg-Gd-Y-Zn-Zr alloy sheets processed by severe hot rolling, J. Alloys Compd. 524 (2012) 46-52.

[14] C. Xu, G.H. Fan, T. Nakata, X. Liang, Y. Q. Chi, X. G. Qiao, G. J. Cao, T. T. Zhang, M. Huang, K. S. Miao, M. Y. Zheng, S. Kamado, H. L. Xie, Deformation behavior of ultra-strong and ductile Mg-Gd$\mathrm{Y}-\mathrm{Zn}-\mathrm{Zr}$ alloy with bimodal microstructure, Metall. Mater. Trans. A 49 (2018) 1931-1947

[15] C. Xu, M.Y. Zheng, S.W. Xu, K. Wu, E.D. Wang, G.H. Fan, S. Kamado, X.D. Liu, G.J. Wang, X.Y. Lv, Microstructure and mechanical properties of $\mathrm{Mg}-\mathrm{Gd}-\mathrm{Y}$ $\mathrm{Zn}-\mathrm{Zr}$ alloy sheets processed by combined processes of extrusion, hot rolling and ageing, Mater. Sci. Eng. A 559 (2013) 844-851.

[16] M. Yamasaki, T. Anan, S. Yoshimoto, Y. Kawamura, Mechanical properties of warm-extruded $\mathrm{Mg}-\mathrm{Zn}-\mathrm{Gd}$ alloy with coherent $14 \mathrm{H}$ long periodic stacking ordered structure precipitate, Scr. Mater. 53 (2005) 799-803.

[17] J. Kim, Y. Kawamura, Influence of rare earth 
elements on microstructure and mechanical properties of $\mathrm{Mg}_{97} \mathrm{Zn}_{1} \mathrm{Y}_{1} \mathrm{RE}_{1}$ alloys, Mater. Sci. Eng. A 573 (2013) 6266.

[18] Y.Q. Chi, M.Y. Zheng, C. Xu, Y.Z. Du, X.G. Qiao, K. Wu, X.D. Liu, G.J. Wang, X.Y. Lv, Effect of ageing treatment on the microstructure, texture and mechanical properties of extruded Mg-8.2Gd-3.8Y-1Zn-0.4Zr (wt.\%) alloy, Mater. Sci. Eng. A 565 (2013) 112-117.

[19] C. Xu, T. Nakata, X.G. Qiao, M.Y. Zheng, K. Wu, S. Kamado, Effect of LPSO and SFs on microstructure evolution and mechanical properties of $\mathrm{Mg}-\mathrm{Gd}-\mathrm{Y}-\mathrm{Zn}-\mathrm{Zr}$ alloy, Sci. Rep. 7 (2017) 40846.

[20] R.B. Figueiredo, T.G. Langdon, Fabricating ultrafine-grained materials through the application of severe plastic deformation: a review of developments in Brazil, J. Mater. Sci. Technol. 1 (2012) 55-62.

[21] W.T. Sun, C. Xu, X.G. Qiao, M.Y. Zheng, S. Kamado, N. Gao, M.J. Starink, Evolution of microstructure and mechanical properties of an as-cast Mg-8.2Gd-3.8Y-1.0Zn-0.4Zr alloy processed by high pressure torsion, Mater. Sci. Eng. A 700 (2017) 312-320. [22] J. Crump, X. G. Qiao, M.J. Starink, The effect of high-pressure torsion on the behaviour of intermetallic particles present in $\mathrm{Al}-1 \mathrm{Mg}$ and $\mathrm{Al}-3 \mathrm{Mg}, \mathrm{J}$. Mater. Sci. 47 (2012) 1751-1757.

[23] B. Adamczyk-Cieślak, J. Mizera, K. J. Kurzydłowski, Microstructures in the 6060 aluminium alloy after various severe plastic deformation treatments, Mater. Charact. 62 (2011) 327-332.

[24] Y. Ivanishenko, W. Lojkowski, R.Z. Valiev, H.-J. Fecht, The mechanism of formation of nanostructure and dissolution of cementite in a pearlitic steel during high pressure torsion, Acta Mater. 51 (2003) 5555-5570.

[25] Q. Yang, B.L. Xiao, Q. Zhang, M.Y. Zheng, Z.Y. $\mathrm{Ma}$, Exceptional high-strain-rate superplasticity in MgGd-Y-Zn-Zr alloy with long-period stacking ordered phase, Scr. Mater. 69 (2013) 801-804.

[26] H. Liu, J. Ju, X.W. Yang, J.L. Yan, D. Song, J.H. Jiang, A.B Ma, A two-step dynamic recrystallization induced by LPSO phases and its impact on mechanical property of severe plastic deformation processed Mg97Y2Zn1 alloy, J. Alloys Compd. 704 (2017) 509517.

[27] H. Liu, J. Ju, F.M. Lu, J.L. Yan, J. Bai, J.H. Jiang, A.B. Ma, Dynamic precipitation behavior and mechanical property of an $\mathrm{Mg}_{94} \mathrm{Y}_{4} \mathrm{Zn}_{2}$ alloy prepared by multi-pass successive equal channel angular pressing, Mater. Sci. Eng. A 682 (2017) 255-259.

[28] B. Chen, D.L. Lin, X.Q. Zeng, C. Lu, Microstructure and mechanical properties of ultrafine grained $\mathrm{Mg}_{97} \mathrm{Y}_{2} \mathrm{Zn}_{1}$ alloy processed by equal channel angular pressing, J. Alloy. Compd. 440 (2007) 94-100.

[29] C. Xu, M.Y. Zheng, Y.Q. Chi, X.J. Chen, K. Wu, E.D. Wang, G.H. Fan, P. Yang, G.J. Wang, X.Y. Lv, S.W.
$\mathrm{Xu}, \quad \mathrm{S}$. Kamado, Microstructure and mechanical properties of the $\mathrm{Mg}-\mathrm{Gd}-\mathrm{Y}-\mathrm{Zn}-\mathrm{Zr}$ alloy fabricated by semi-continuous casting, Mater. Sci. Eng. A 549 (2012) 128-135.

[30] K. Edalati, Z. Horita, A review on high-pressure torsion (HPT) from 1935 to 1988, Mater. Sci. Eng. A 652 (2016) 325-352.

[31] A. Thorvaldsen, The intercept method-1. Evaluation of grain shape, Acta Mater. 45 (1997) 587-594.

[32] M.J. Starink, X.G. Qiao, J. Zhang, N. Gao, Predicting grain refinement by cold severe plastic deformation in alloys using volume averaged dislocation generation, Acta Mater. 57 (2009) 5796-5811.

[33] Y. Chen, N. Gao, G. Sha, S.P. Ringer, M.J. Starink, Microstructural evolution, strengthening and thermal stability of an ultrafine-grained Al-Cu-Mg alloy, Acta Mater. 109 (2016) 202-212.

[34] E. Underwood, Quantitative stereology, AddisonWesley Pub. Co., 1970.

[35] J.J. Bhattacharyya, S.R. Agnew, G. Muralidharan, Texture enhancement during grain growth of magnesium alloy AZ31B, Acta Mater. 86 (2015) 80-94.

[36] M. Ferrari, L. Lutterotti, Method for the simultaneous determination of anisotropic residual stresses and texture by X-ray diffraction, J. Appl. Phys. 76 (1994) 7246-7255.

[37] L. Lutterotti, S. Gialanella, X-ray diffraction characterization of heavily deformed metallic specimens, Acta Mater. 46 (1998) 101-110.

[38] G.K. Williamson, R.E. Smallman, Dislocation densities in some annealed and cold-worked metals from measurements on the X-Ray debye-scherrer spectrum, Philos. Mag. 1 (1956) 34-46.

[39] M.Y. Murashkin, I. Sabirov, A.E. Medvedev, N.A. Enikeev, W. Lefebvre, R.Z. Valiev, X. Sauvage, Mechanical and electrical properties of an ultrafine grained Al-8.5 wt. \% RE (RE = 5.4 wt.\% Ce, 3.1 wt.\% La) alloy processed by severe plastic deformation, Mater. Des. 90 (2016) 433-442.

[40] Pandat software and PanMg database, Release Date: 2017, CompuTherm LLC, Madison, WI, USA, http://www.computherm.com.

[41] I. Saunders, J. Nutting, Deformation of metals to high strains using combination of torsion and compression, Met. Sci. 18 (1984) 571-575.

[42] X.G. Qiao, Y.W. Zhao, W.M. Gan, Y. Chen, M.Y. Zheng, K. Wu, N. Gao, M.J. Starink, Hardening mechanism of commercially pure $\mathrm{Mg}$ processed by high pressure torsion at room temperature, Mater. Sci. Eng. A 619 (2014) 95-106.

[43] W.T. Sun, X.G. Qiao, M.Y. Zheng, C. Xu, N. Gao, M.J. Starink, Microstructure and mechanical properties of a nanostructured Mg-8.2Gd-3.8Y-1.0Zn-0.4Zr supersaturated solid solution processed by high pressure 
torsion, Mater. Des. 135 (2017) 366-376.

[44] X.X. Lv, H.Y. Liu, Y.B. Wang, Y. Lu, G.Y. Li, J. An, Microstructure and dry sliding wear behavior of Mg-Y$\mathrm{Zn}$ alloy modified by laser surface melting, J. Mater. Eng. Perform. 20 (2011) 1015-1022.

[45] J. Gubicza, Chapter 3 - Defect structure in bulk nanomaterials processed by severe plastic deformation, In defect structure and properties of nanomaterials (2nd Edition), Woodhead Publishing, 2017, 59-93.

[46] J. Vrátná, M. Janeček, J. Čížek, D.J. Lee, E.Y. Yoon, H.S. Kim, Mechanical properties and microstructure evolution in ultrafinegrained AZ31 alloy processed by severe plastic deformation, J. Mater. Sci. 48 (2013) 47054712.

[47]A.S.J. Al-

Zubaydi, A.P. Zhilyaev, S.C. Wang, P. Kucita, P.A.S. R eed, Evolution of microstructure in AZ91 alloy processed by high-pressure torsion, J. Mater. Sci. 51 (2016) 33803389.

[48] T. Ungár, J. Gubicza, G. Ribárik, A. Borbély, Crystallite size distribution and dislocation structure determined by diffraction profile analysis: principles and practical application to cubic and hexagonal crystals, J. Appl. Cryst. 34 (2001) 298-310.

[49] J. Peng, L.P. Zhong, Y.J. Wang, Y. Lu, F.S. Pan, Effect of extrusion temperature on the microstructure and thermal conductivity of $\mathrm{Mg}-2.0 \mathrm{Zn}-1.0 \mathrm{Mn}-0.2 \mathrm{Ce}$ alloys, Mater. Des. 87 (2015) 914-919.

[50] Q.M. Peng, J. Meng, Y.D. Li, Y.D. Huang, N. Hort, Effect of yttrium addition on lattice parameter, Young' $\mathrm{s}$ modulus and vacancy of magnesium, Mater. Sci. Eng. A 528 (2011) 2106-2109.

[51] H.L. Ding, X.B. Shi, Y.Q. Wang, G.P. Cheng, S. Kamado, Texture weakening and ductility variation of $\mathrm{Mg}-2 \mathrm{Zn}$ alloy with $\mathrm{Ca}$ or RE addition, Mater. Sci. Eng. A 645 (2015) 196-204.

[52] F. Yang, T.W. Fan, J. Wu, B.Y. Tang, L.M. Peng, W.J. Ding, Effects of $\mathrm{Y}$ and $\mathrm{Zn}$ atoms on the elastic properties of $\mathrm{Mg}$ solid solution from first-principles calculations, Phys. Status Solidi B 248 (2011) 2809-2815.

[53] M. Matsushita, Y. Sakata, T. Senzaki, M. Yamasaki, I. Yamada, H. Saitoh, T. Shinmei, T. Irifune, N. Nishiyama, Y. Kawamura, Phase relations among $\mathrm{D0}_{3}, \alpha-$ $\mathrm{Mg}$, and long-period stacking orders in $\mathrm{Mg}_{85} \mathrm{Zn}_{6} \mathrm{Y}_{9}$ alloy under 3 GPa, Mater. Trans. 56 (2015) 910-913.

[54] G. Garces, M.A. Muñoz-Morris, D.G. Morris, P. Perez, P. Adeva, Optimization of strength by microstructural refinement of $\mathrm{MgY}_{2} \mathrm{Zn}_{1}$ alloy during extrusion and ECAP processing, Mater. Sci. Eng. A 614 (2014) 96-105.

[55] F.M. Lu, A.B. Ma. J.H. Jiang, D.H. Yang, Y.C. Yuan, L.Y. Zhang, Formation of profuse long period stacking ordered microcells in $\mathrm{Mg}-\mathrm{Gd}-\mathrm{Zn}-\mathrm{Zr}$ alloy during multipass ECAP process, J. Alloys Compd. 601 (2014) 140-145.

[56] F.M. Lu, A.B. Ma, J.H. Jiang, D.H. Yang, D. Song, Y.C. Yuan, J. Chen, Effect of multi-pass equal channel angular pressing on microstructure and mechanical properties of $\mathrm{Mg}_{97.1} \mathrm{Zn}_{1} \mathrm{Gd}_{1.8} \mathrm{Zr}_{0.1}$ alloy, Mater. Sci. Eng. A 594 (2014) 330-333.

[57] M.J. Starink, X. Cheng, S. Yang, Hardening of pure metals by high-pressure torsion: A physically based model employing volume-averaged defect evolutions, Acta Mater. 61 (2013) 183-192.

[58] Z.C. Cordero, B.E. Knight, C.A. Schuh, Six decades of the Hall-Petch effect-a survey of grain-size strengthening studies on pure metals, Int. Mater. Rev. 61 (2016) 495-512.

[59] M.J. Starink, Dislocation versus grain boundary strengthening in SPD processed metals: non-causal relation between grain size and strength of deformed polycrystals. Mater. Sci. Eng. A 705 (2017) 42-45.

[60] L. Gao, R.S. Chen, E.H. Han, Effects of rare-earth elements Gd and Y on the solid solution strengthening of Mg alloys, J. Alloys Compd. 481 (2009) 379-384. 


\section{Supplementary Material}

In addition, the HPT-processed Mg-Gd-Y-Zn-Zr alloy containing LPSO phase was further annealed at $400{ }^{\circ} \mathrm{C}$ for $1 \mathrm{~h}$ followed by water quenching, and the microstructure is shown in Fig. S1. According to the composition analysis by EDS shown in Fig. S1 (b)-(d), the lamellae in rectangular region indicated by $\mathrm{C}$ are $14 \mathrm{H} \mathrm{LPSO}\left(\mathrm{Mg}_{12} \mathrm{RE}_{1} \mathrm{Zn}_{1}\right.$ [9]), and the particles marked by B and block-shaped phase marked by $\mathrm{D}$ are RE-rich compound and $\mathrm{Mg}_{5}(\mathrm{Gd}, \mathrm{Y}, \mathrm{Zn})$ phase, respectively. This indicates that after heat treatment of the nanostructured Mg-Gd-Y-Zn-Zr alloy, the LPSO phase will form again.
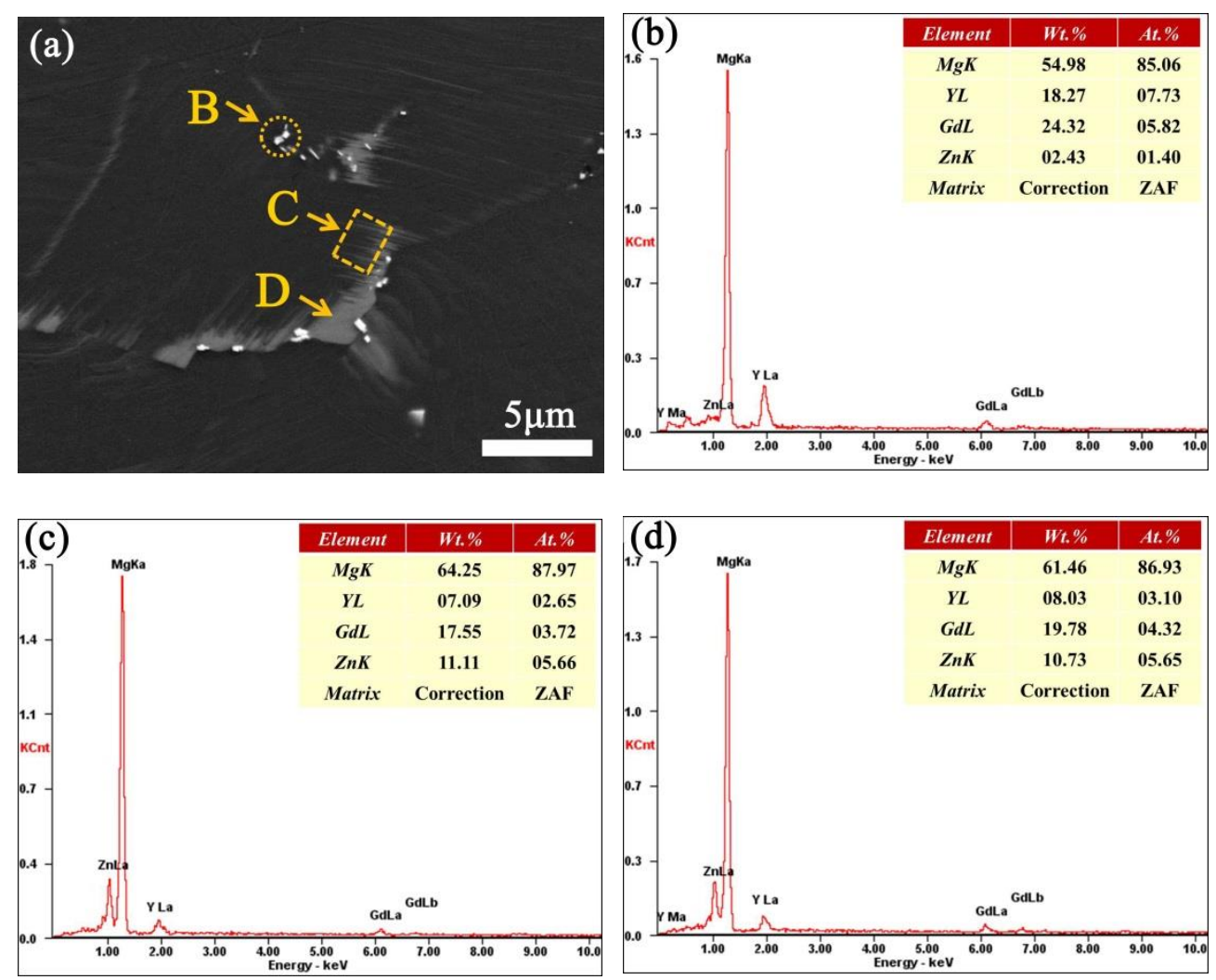

Fig. S1 (a) SEM micrograph of the HPT-processed alloy annealing at $400{ }^{\circ} \mathrm{C}$ for $1 \mathrm{~h}$; (b), (c) and (d) are the EDS results of the phases marked $\mathrm{B}, \mathrm{C}$ and $\mathrm{D}$ in (a). 